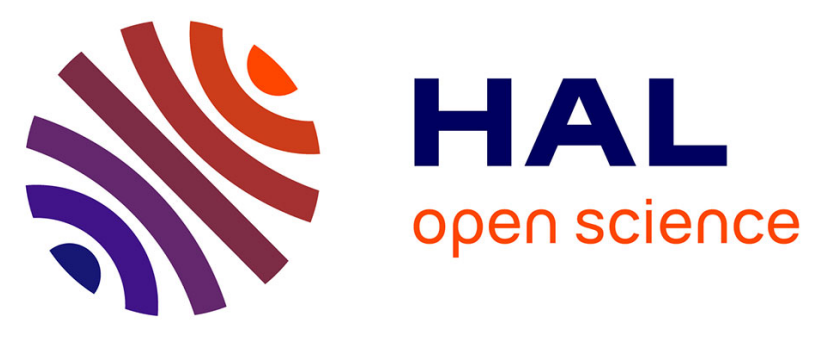

\title{
How does calcium drive the structural organization of iron-organic matter aggregates? A multiscale investigation
}

\author{
Anthony Beauvois, Delphine Vantelon, Jacques Jestin, Camille Rivard, \\ Martine Bouhnik-Le Coz, Aurélien Dupont, Valérie Briois, Thomas Bizien, \\ Andrea Sorrentino, Baohu Wu, et al.
}

\section{To cite this version:}

Anthony Beauvois, Delphine Vantelon, Jacques Jestin, Camille Rivard, Martine Bouhnik-Le Coz, et al.. How does calcium drive the structural organization of iron-organic matter aggregates? A multiscale investigation. Environmental science.Nano, 2020, 7 (9), pp.2833-2849. 10.1039/D0EN00412J . insu02916815

\section{HAL Id: insu-02916815 https://hal-insu.archives-ouvertes.fr/insu-02916815}

Submitted on 18 Aug 2020

HAL is a multi-disciplinary open access archive for the deposit and dissemination of scientific research documents, whether they are published or not. The documents may come from teaching and research institutions in France or abroad, or from public or private research centers.
L'archive ouverte pluridisciplinaire HAL, est destinée au dépôt et à la diffusion de documents scientifiques de niveau recherche, publiés ou non, émanant des établissements d'enseignement et de recherche français ou étrangers, des laboratoires publics ou privés. 
Nano

\section{Accepted Manuscript}

This article can be cited before page numbers have been issued, to do this please use: A. Beauvois, D. vantelon, J. Jestin, C. Rivard, M. Bouhnik-Le-Coz, A. Dupont, V. Briois, T. Bizien, A. Sorrentino, B. Wu, M. Appavou, E. Lotfi-Kalahroodi, A. pierson-wickmann and M. Davranche, Environ. Sci.: Nano, 2020, DOI:

\section{Environmental Science Nano}

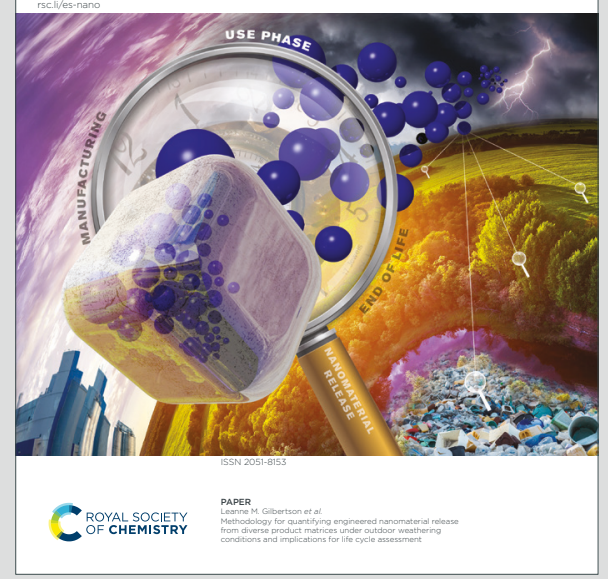

This is an Accepted Manuscript, which has been through the Royal Society of Chemistry peer review process and has been accepted for publication.

Accepted Manuscripts are published online shortly after acceptance, before technical editing, formatting and proof reading. Using this free service, authors can make their results available to the community, in citable form, before we publish the edited article. We will replace this Accepted Manuscript with the edited and formatted Advance Article as soon as it is available.

You can find more information about Accepted Manuscripts in the Information for Authors.

Please note that technical editing may introduce minor changes to the text and/or graphics, which may alter content. The journal's standard Terms \& Conditions and the Ethical guidelines still apply. In no event shall the Royal Society of Chemistry be held responsible for any errors or omissions in this Accepted Manuscript or any consequences arising from the use of any information it contains. 


\section{Environmental Significance Statement}

In environmental systems, the production of iron-organic matter (Fe-OM) nano-aggregates has been significantly increasing in recent decades due to climate change. These nano-aggregates are expected to be a major controlling factor of micro-pollutant mobility. Herein, we demonstrate that with an increasing $\mathrm{Ca}$ concentration, $\mathrm{Fe}-\mathrm{OM}$ structures move from nanometric aggregates to a micrometric network in which the size of Fe phases increases. These results shed new light on the mobility of Fe-OM aggregates and potentially associated micro-pollutants that seems to depend on Fe-OM organization which is modified by major ion species present during their production. These findings are of major importance to discern the structure and behaviour of Fe-OM colloids in their production areas such as riparian wetlands, soil erosions or permafrost thawing. 


\section{How does calcium drive the structural organization of iron-organic matter aggregates?}

\section{A multiscale investigation}

Anthony Beauvois*a,b,c , Delphine Vantelon ${ }^{\mathrm{b}}$, Jacques Jestin ${ }^{\mathrm{c}}$, Camille Rivard ${ }^{\mathrm{b}, \mathrm{d}}$, Martine Bouhnik-Le Coz ${ }^{\mathrm{a}}$, Aurélien Dupont ${ }^{\mathrm{e}}$, Valérie Briois ${ }^{\mathrm{b}}$, Thomas Bizien ${ }^{\mathrm{b}}$, Andrea Sorrentino ${ }^{\mathrm{f}}$, Baohu $\mathrm{Wu}^{\mathrm{g}}$, Marie-Sousai Appavou ${ }^{\mathrm{g}}$, Elaheh LotfiKalahroodi $^{\mathrm{a}}$, Anne-Catherine Pierson-Wickmann ${ }^{\mathrm{a}}$ and Mélanie Davranche ${ }^{\mathrm{a}}$ ${ }^{a}$ Univ. Rennes, CNRS, Géosciences Rennes - UMR 6118, F-35000 Rennes, France ${ }^{b}$ Synchrotron SOLEIL, L'Orme des Merisiers, Saint-Aubin BP48, 91192 Gif-sur-Yvette Cedex ${ }^{c}$ Laboratoire Léon Brillouin, CEA Saclay, 91191 Gif-sur-Yvette Cedex ${ }^{d}$ INRAE - UAR 1008 TRANSFORM, F-44316 Nantes, France eUniv Rennes, CNRS, Inserm, BIOSIT - UMS 3480, US_S 018, F-35000 Rennes, France ${ }^{f}$ ALBA Synchrotron Light Facility, Carrer de la Llum 2-26, 08290 Cerdanyola del Vallès, Spain gForschungszentrum Jülich, JCNS am MLZ, Lichtenbergstr. 1, 85748 Garching, Germany *Corresponding author: anthony.beauvois@univ-rennes1.fr

\footnotetext{
$\underline{\text { Abstract }}$

Iron-organic matter (Fe-OM) aggregates are a key factor in the control of pollutant mobility. Their physical and structural organization depends on the prevailing physicochemical
} 
conditions during their formation and on subsequent exposure to variations in poreryigateficle Online goechemistry. Among these conditions, calcium (Ca) could be a major parameter given its high concentrations in the environment and its affinity for OM. Mimetic environmental Fe-OM-Ca associations were synthesized at various Fe/organic carbon (OC) and $\mathrm{Ca} / \mathrm{Fe}$ molar ratios using Leonardite humic acid as OM model. The impact of Ca on Fe-OM aggregates was studied by a combination of X-ray absorption spectroscopy, small angle X-ray and neutron scattering and imaging techniques (TEM, cryo-TEM and cryo-TXM). Iron phases are constituted of Fe(III)oligomers, Fe(III)-nanoparticles and ferrihydrite (Fh), all bound or embedded by OM. Iron phases exhibit a fractal organization with Fe-primary beads aggregated as Fe-primary aggregates (Fe-PA) which themselves are embedded in an $\mathrm{OM}$ aggregates. For $\mathrm{Ca} / \mathrm{OC}$ $(\mathrm{mol} / \mathrm{mol})<0.026, \mathrm{Fe}-\mathrm{PA}$ aggregate in a third level as a Fe-secondary aggregate. For $\mathrm{Ca} / \mathrm{OC} \geq$ 0.026, $\mathrm{OM}$ forms a large Ca-branched network in which $\mathrm{Ca}$ is bound as a dimer to $\mathrm{OM}$ carboxylic sites. In such conditions, Fe-PA are distributed in the OM network, distant from each other. All these structural transitions are driven by $\mathrm{Ca}$ which partially screens the $\mathrm{Fe}-\mathrm{OM}$ interactions. The formation of such micrometric network should impact both the surface reactivity of the $\mathrm{Fe}$ phases as well as the mobility of $\mathrm{Fe}, \mathrm{OM}$ and associated elements, notably in the soil porosity where they are produced under natural conditions. 


\section{Introduction}

Environmental nanoparticles are ubiquitous in natural systems ${ }^{1}$. Among them, natural ironorganic matter (Fe-OM) aggregates are of major importance due to their high amounts in natural systems such as in wetlands ${ }^{2-4}$, peatlands ${ }^{5,6}$ or permafrosts ${ }^{7,8}$. They are mainly produced in soils via anthropogenic forcing and geochemical and physical processes such as alteration and erosion, oxidation-reduction variations occurrence subsequent to soil watersaturation/desaturation alternation. The production of these aggregates has tended to strongly increase in recent decades due to global warming which result in an increase in rainfall frequency, volume and intensity as well as permafrost thawing. Due to their nanometric size and their high specific surface area, they are known to be a key factor in the mobility of metals and metalloids in environmental systems $\mathrm{s}^{1,2,6,9,10}$. Their ability to adsorb metal(loid)s depends on the size, morphology and structural arrangement between the Fe and OM phases ${ }^{11,12}$. Several studies have investigated the structural organization of Fe phases formed during $\mathrm{Fe}(\mathrm{II})$ oxidation-hydrolysis or $\mathrm{Fe}(\mathrm{III})$ hydrolysis in the presence of $\mathrm{OM}^{13-18}$. Irrespective of the process of formation, the Fe speciation depends on the Fe/organic carbon (OC) ratio. For very low $\mathrm{Fe} / \mathrm{OC}$ ratios, the dominant $\mathrm{Fe}$ species are $\mathrm{Fe}(\mathrm{III})$ oligomers bound to $\mathrm{OM}^{11,19}$ while for high $\mathrm{Fe} / \mathrm{OC}$ ratio, nanoparticulate $\mathrm{Fe}$ embedded in an $\mathrm{OM}$ matrix are formed ${ }^{20,21}$. For intermediate $\mathrm{Fe} / \mathrm{OC}$ ratios, Fe-OM aggregates contain two distinct Fe phases: $\mathrm{Fe}(\mathrm{III})$ oligomers bound to OM and nano-sized ferrihydrite (Fh) embedded in an OM matrix ${ }^{14,18,22}$. According to Chen et al. ${ }^{18}$, a decrease in $\mathrm{Fe}(\mathrm{III})$ oligomers occurs to the benefit of Fh with an increasing $\mathrm{Fe} / \mathrm{OC}$ ratio. Guénet et al. ${ }^{13}$ demonstrated that the Fe part is organized according to a fractal network composed of Fe primary beads (radius $\approx 0.8 \mathrm{~nm}$ ) that associate to form Fe primary aggregates (radius $\approx 5 \mathrm{~nm}$ ) that are themselves associated as Fe secondary aggregates (radius $>$ $100 \mathrm{~nm}$ ). They described the $\mathrm{OM}$ part as a compact aggregate (radius $\approx 90 \mathrm{~nm}$ ) bound to $\mathrm{Fe}$ 
secondary aggregates as well as isolated molecules bound to Fe primary aggregates: The of Fe-OM aggregates increases with the increasing Fe/OC ratio.

These species were also observed in organic soil as Fe monomers and Fe oxyhydroxides bound to $\mathrm{OM}^{22}$ and in boreal rivers as nano-Fh and Fe-OM complexes ${ }^{23}$. ThomasArrigo et al. $^{6}$ reported the presence of lepidocrocite (Lp) and $\mathrm{Fh}$ in a peatland soil. Guénet et al. ${ }^{2}$ studied a riparian wetland soil and provided evidence of the presence of nano-Lp embedded in an OM matrix, as well as small Fe clusters (i.e. oligomers) and Fe monomers bound to OM.

In the absence of $\mathrm{OM}, \mathrm{Fe}(\mathrm{II})$ oxidation-hydrolysis leads to the formation of micrometric-sized aggregates of nano-Lp ${ }^{17,24}$ whereas with humic acid (HA), Fe oxyhydroxides of nanometric size are formed ${ }^{2,14,17}$. Therefore, organic matter controls the behaviour of $\mathrm{Fe}$ in organic environments and the physical, chemical and morphological organization of $\mathrm{Fe}-\mathrm{OM}$ aggregates is influenced by the prevailing physico-chemical conditions such as $\mathrm{pH}$, ionic strength or other major cations ${ }^{25-27}$. In natural waters, calcium $(\mathrm{Ca})$ is a major ion with a concentration ranging from $1.0 \times 10^{-2}$ to $1.0 \times 10^{-4} \mathrm{~mol} \mathrm{~L}^{-128}$. Several studies have investigated the impact of $\mathrm{Ca}$ on the structural organization of natural OM. Calcium acts as a coagulating agent for OM by forming cationic bridges between molecules, preferentially involving carboxylic groups ${ }^{29-31}$ but also via phenolic groups with increasing $\mathrm{pH}$ values ${ }^{32}$. Kalinichev and Kirkpatrick ${ }^{31}$ reported the formation of $\mathrm{OM}$ supramolecular structures with $\mathrm{Ca}$. Calcium has also been shown to increase the adsorption of fulvic acids (FA) on goethite ${ }^{33}$ leading to the formation of goethite-Ca-FA ternary associations, and to aggregate $\mathrm{OM}$ with clay minerals ${ }^{34}$. Adhikari et al. ${ }^{35}$ provided evidence that the hydrolysis of $\mathrm{Fe}(\mathrm{III})$ with $\mathrm{OM}$ and $\mathrm{Ca}$ leads to the formation of Fh-OM-Ca precipitates in which $\mathrm{OM}$ acts as a bridge between $\mathrm{Fh}$ and $\mathrm{Ca}$. Davis and Edwards ${ }^{36}$ demonstrated that $\mathrm{Ca}^{2+}$ complexation by $\mathrm{OM}$ enhances $\mathrm{Fe}(\mathrm{III})$ hydrolysis resulting in better polymerization of Fe with $\mathrm{Ca}$. However, there are lacks of information on the overall structural organization of Fe-OM-Ca associations. 
The aim of this study is therefore to provide a complete characterization of the impact of Ciawditicle Online the composition and structural organization of Fe-OM aggregates. For this purpose, we synthesized $\mathrm{Fe}-\mathrm{OM}-\mathrm{Ca}$ associations with various $\mathrm{Fe} / \mathrm{OC}$ and $\mathrm{Ca} / \mathrm{Fe}$ ratios. Calcium interactions with Fe-OM and Fe speciation were investigated by X-ray absorption spectroscopy (XAS) at the $\mathrm{Ca}$ and $\mathrm{Fe} \mathrm{K}$-edge. The arrangement of nanoparticulate $\mathrm{Fe}$ and $\mathrm{OM}$ was probed combining small-angle X-rays scattering (SAXS), small-angle neutrons scattering (SANS) and very smallangle neutrons scattering (VSANS). The overall size of the aggregates was investigated by cryo-transmission X-ray microscopy (cryo-TXM) and cryo-transmission electron microscopy (cryo-TEM).

\section{$\underline{\text { Experimental methods }}$}

\section{Sampling and chemical analyses}

\subsection{Laboratory syntheses}

All aqueous solutions were prepared with ultrapure water (Milli-Q-Integral ${ }^{\circledR}$, Millipore). Samples were synthesized at three Fe/OC molar ratios (i.e. $0.02,0.05$ and 0.08 ) and at four $\mathrm{Ca} / \mathrm{Fe}$ molar ratios (i.e. 0, 0.1, 0.5 and 1) following the procedure described by Guénet et al. ${ }^{13}$. Samples were labelled Fexx-Cayy, where Fexx and Cayy represent the $\mathrm{Fe} / \mathrm{OC}$ and the $\mathrm{Ca} / \mathrm{Fe}$ ratios, respectively. The OM used was Leonardite Humic Acid (HA) (International Humic Substances Society) with the elemental composition $\mathrm{C}=63.81 \%, \mathrm{O}=31.27 \%, \mathrm{H}=3.70 \%$ and $\mathrm{N}=1.23 \%$ (as a mass fraction). A $1.79 \times 10^{-2} \mathrm{~mol} \mathrm{~L}^{-1}$ iron(II) stock solution was prepared with $\mathrm{FeCl}_{2} \cdot 4 \mathrm{H}_{2} \mathrm{O}$ (Sigma Aldrich). From this solution, three $\mathrm{Fe}(\mathrm{II})-\mathrm{Ca}(\mathrm{II})$ stock solutions were prepared at $[\mathrm{Ca}]=2.50 \times 10^{-3} \mathrm{~mol} \mathrm{~L}^{-1}, 1.25 \times 10^{-2} \mathrm{~mol} \mathrm{~L}^{-1}$ and $2.50 \times 10^{-2} \mathrm{~mol} \mathrm{~L}^{-1}$ with $\mathrm{CaCl}_{2} \cdot 2 \mathrm{H}_{2} \mathrm{O}$ (Sigma Aldrich). Aggregates (Fe-OM-Ca) were synthesized using a titration of a HA suspension at $[\mathrm{OC}]=1.00 \times 10^{-1} \mathrm{~mol} \mathrm{~L}^{-1}$ with the $\mathrm{Fe}(\mathrm{II})-\mathrm{Ca}(\mathrm{II})$ solution at $0.05 \mathrm{~mL} \mathrm{~min}^{-1}$ in $5 \times 10^{-}$ ${ }^{3} \mathrm{~mol} \mathrm{~L}^{-1}$ of $\mathrm{NaCl}$ using an automated titrator (Titrino 794, Metrohm). The $\mathrm{pH}$ was kept constant 


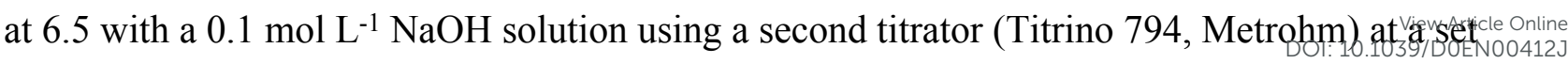
$\mathrm{pH}$ mode. The accuracy of the $\mathrm{pH}$ measurement was $\pm 0.04 \mathrm{pH}$ units. A fraction of each sample was subjected to filtration at $0.2 \mu \mathrm{m}$ (cellulose acetate membrane filter, Sartorius) and ultrafiltration at $30 \mathrm{kDa}$ (Vivaspin VS2022, Sartorius). Each $0.2 \mu \mathrm{m}$ filter was rinsed before use with ultrapure water and each $30 \mathrm{kDa}$ ultrafiltration cell was rinsed 10 times with $\mathrm{NaOH} 0.1$ mol L-1 and two times with ultrapure water. Two samples were also prepared using the same protocol but without $\mathrm{Fe}$ at $\mathrm{Ca}$ concentrations of $1.00 \times 10^{-4}$ and $5.00 \times 10^{-3} \mathrm{~mol} \mathrm{~L}^{-1}$.

\subsection{Chemical analyses}

OC concentrations were determined using an organic carbon analyser (Shimadzu TOC-V $\mathrm{CSH})$. The accuracy of the $\mathrm{OC}$ measurement was determined to be $\pm 5 \%$ using a standard solution of potassium hydrogen phthalate (Sigma Aldrich). The Fe and Ca concentrations were measured by ICP-MS using an Agilent Technologies 7700x instrument at the University of Rennes 1. To eliminate OM, samples were pre-digested with $14.6 \mathrm{~mol} \mathrm{~L}^{-1} \mathrm{HNO}_{3}$ and suprapure ${ }^{\circledR} 30 \% \mathrm{H}_{2} \mathrm{O}_{2}$ at $90^{\circ} \mathrm{C}$ and evaporated. The final concentrations of $\mathrm{Fe}, \mathrm{Ca}$, and $\mathrm{OC}$ are reported in Table 1 for the bulk and in Table SI 1 for the filtrates and ultrafiltrates. 
Table $1-\mathrm{Fe}, \mathrm{Ca}$ and $\mathrm{OC}$ concentrations. *Theoretical values, n.d.: not determined. Exp: experimental. Theo: theoretical. The uncertainties were calculated from the triplicate.

\begin{tabular}{|c|c|c|c|c|c|c|c|c|}
\hline \multirow{2}{*}{$\begin{array}{l}\text { Sample } \\
\text { name }\end{array}$} & \multirow{2}{*}{ 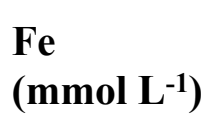 } & \multirow{2}{*}{$\begin{array}{l}\mathrm{Ca} \\
\left.(\mathbf{m m o l ~ L})^{-1}\right)\end{array}$} & \multirow{2}{*}{$\begin{array}{l}\mathrm{OC} \\
\left(\mathbf{m m o l ~ L} \mathbf{L}^{-1}\right)\end{array}$} & \multicolumn{2}{|c|}{$\mathrm{Ca} / \mathrm{Fe}(\mathrm{mol} / \mathrm{mol})$} & \multicolumn{2}{|c|}{$\mathrm{Fe} / \mathrm{OC}(\mathrm{mol} / \mathrm{mol})$} & \multirow{2}{*}{$\begin{array}{l}\mathrm{Ca} / \mathrm{OC}(\mathrm{mol} / \mathrm{mol}) \\
\operatorname{Exp}\end{array}$} \\
\hline & & & & $\operatorname{Exp}$ & Theo & $\operatorname{Exp}$ & Theo & \\
\hline $\mathrm{Fe} 0.00-\mathrm{Ca} \_4$ & $0 *$ & $0.10^{*}$ & $58.0 *$ & - & - & n.d. & 0.00 & 0.002 \\
\hline $\mathrm{Fe} 0.00-\mathrm{Ca} \_200$ & $0 *$ & $5.00 *$ & $58.0 *$ & - & - & n.d. & 0.00 & 0.091 \\
\hline $\mathrm{Fe} 0.02-\mathrm{Ca} 0.0$ & $1.21 \pm 0.05$ & $0.10 \pm 0.01$ & $56.3 \pm 0.9$ & 0.10 & 0.10 & 0.02 & 0.02 & 0.002 \\
\hline $\mathrm{Fe} 0.02-\mathrm{Ca} 0.1$ & $1.07 \pm 0.09$ & $0.22 \pm 0.02$ & $54.3 \pm 1.0$ & 0.09 & 0.10 & 0.02 & 0.02 & 0.004 \\
\hline $\mathrm{Fe} 0.02-\mathrm{Ca} 0.5$ & $1.20 \pm 0.08$ & $0.65 \pm 0.04$ & $57.7 \pm 1.7$ & 0.10 & 0.10 & 0.02 & 0.02 & 0.011 \\
\hline $\mathrm{Fe} 0.02-\mathrm{Ca} 1.0$ & $1.30 \pm 0.03$ & $1.28 \pm 0.04$ & $55.8 \pm 0.2$ & 0.11 & 0.10 & 0.02 & 0.02 & 0.023 \\
\hline $\mathrm{Fe} 0.05-\mathrm{Ca} 0.0$ & $2.98 \pm 0.22$ & $0.10 \pm 0.01$ & $55.5 \pm 0.9$ & 0.25 & 0.25 & 0.05 & 0.05 & 0.002 \\
\hline $\mathrm{Fe} 0.05-\mathrm{Ca} 0.1$ & $3.23 \pm 0.08$ & $0.40 \pm 0.01$ & $55.5 \pm 0.1$ & 0.27 & 0.25 & 0.06 & 0.05 & 0.007 \\
\hline $\mathrm{Fe} 0.05-\mathrm{Ca} 0.5$ & $2.80 \pm 0.13$ & $1.45 \pm 0.06$ & $55.5 \pm 0.9$ & 0.24 & 0.25 & 0.05 & 0.05 & 0.026 \\
\hline $\mathrm{Fe} 0.05-\mathrm{Ca} 1.0$ & $2.70 \pm 0.12$ & $2.80 \pm 0.09$ & $51.9 \pm 2.8$ & 0.24 & 0.25 & 0.05 & 0.05 & 0.054 \\
\hline $\mathrm{Fe} 0.08-\mathrm{Ca} 0.0$ & $4.75 \pm 0.12$ & $0.10 \pm 0.01$ & $61.6 \pm 1.0$ & 0.36 & 0.40 & 0.08 & 0.08 & 0.002 \\
\hline $\mathrm{Fe} 0.08-\mathrm{Ca} 0.1$ & $5.00 \pm 0.07$ & $0.60 \pm 0.01$ & $60.8 \pm 0.3$ & 0.38 & 0.40 & 0.08 & 0.08 & 0.010 \\
\hline $\mathrm{Fe} 0.08-\mathrm{Ca} 0.5$ & $4.79 \pm 0.10$ & $2.38 \pm 0.07$ & $55.2 \pm 1.9$ & 0.40 & 0.40 & 0.09 & 0.08 & 0.043 \\
\hline $\mathrm{Fe} 0.08-\mathrm{Ca} 1.0$ & $4.95 \pm 0.06$ & $4.73 \pm 0.01$ & $51.8 \pm 1.1$ & 0.44 & 0.40 & 0.10 & 0.08 & 0.091 \\
\hline
\end{tabular}




\subsection{XAS data acquisition and analysis}

A fraction of each sample was freeze dried (Freeze dryer Alpha 1-2 LD plus, Christ). The obtained powder was pressed into a $6 \mathrm{~mm}$ pellet mixed with cellulose (Merck). X-ray absorption spectroscopy (XAS) at the Ca K-edge was performed on the LUCIA ${ }^{37,38}$ beamline at the SOLEIL synchrotron (Saint-Aubin, France). The fixed exit double-crystal monochromator was equipped with $\operatorname{Si}(111)$ crystals. Spectra were recorded in fluorescence mode using a $60 \mathrm{~mm}^{2}$ mono-element silicon drift diode detector (Bruker). The energy was calibrated using the calcite reference for which the first inflection point was set to $4045 \mathrm{eV}$.

The Fe K-edge spectra were recorded on the $\mathrm{ROCK}^{39}$ beamline at the SOLEIL synchrotron. A $\operatorname{Si}(111)$ channel-cut was used as the monochromator. Spectra were recorded in transmission mode using three ionization chambers (Ohyo Koken) filled with $\mathrm{N}_{2}$. The energy was calibrated using a Fe foil located between the $2^{\text {nd }}$ and the $3^{\text {rd }}$ ionization chambers and measured simultaneously with the samples. Calibration was done by setting the maximum of the first derivate of the Fe foil to $7112 \mathrm{eV}$. The spectra were acquired with the quick-EXAFS technology allowing measuring one spectrum every $1 \mathrm{~s}$. For each sample, a total of 1500 spectra were recorded and could be superimposed, suggesting no damage of the sample due to the beam. The final spectrum was obtained by averaging the 1500 spectra. The references used for further data analysis were Fh and Lp synthesized following the procedure described in Schwertmann and Cornel124.

All XAS data were processed using the Athena software ${ }^{40}$ including the Autbk algorithm (Rbkb $=1$, k-weight $=3$ ). Normalized Ca spectra were obtained by fitting the pre-edge region with a linear function and the post-edge region with a quadratic polynomial function. The Fourier transforms of the $\mathrm{k}^{3}$-weighted extended X-ray absorption fine structure (EXAFS) spectra were calculated over a range of 2-10.5 $\AA^{-1}$ using a Hanning apodization window (window parameter 
= 1). Back Fourier filters were extracted over the R-range of 1.3-3.1 A, using the thiambricle Online apozidation window shape. The EXAFS fittings were performed in the 1.3-3.6 $\AA$ distance range with the Artemis ${ }^{40}$ interface to IFEFFIT using least-squares refinements. The paths used to fit the Ca K-edge EXAFS were calculated from Ca-acetate ${ }^{41}$ and $\mathrm{Ca}-2$-furancarboxylate ${ }^{42}$ using the FEFF6 algorithm included in the Artemis interface ${ }^{43,44}$. Normalized Fe spectra were obtained by fitting the pre-edge region with a linear function and the post-edge region with a quadratic polynomial function. The Fourier transforms of the $\mathrm{k}^{3}$-weighted EXAFS spectra were calculated over a range of 2-12.5 $\AA^{-1}$ using a Hanning apodization window (window parameter = 1). Back Fourier filters were extracted over the R-range of 1.15-4.1 $\AA$, using the same apodization window shape. The EXAFS data were analysed by linear combination fitting (LCF) available in the Athena software on the range 3-12.5 $\AA^{-1}$; all component weights were forced to be positive. The references used were Fh, Lp and three pure components extracted from the in situ synthesis of Fe-OM aggregates by Vantelon et al. ${ }^{14}$, i.e. Fe(II), Fe(III)-oligomers and $\mathrm{Fe}(\mathrm{III})-\mathrm{Np}$ that correspond to $\mathrm{Fe}(\mathrm{III})$ nano-oxyhydroxides, all bound or embedded in a HA matrix. The best LCF fit was determined for the minimum $n$-components for which the R-factor was better than $10 \%$ of the fit with $n+1$ components. As without any constraint the total LCF weight for each sample was between 0.95 and 1.05 , it was arbitrarily fixed to 1 to facilitate comparisons between each sample.

\subsection{SAXS data acquisition and analysis}

Small angle X-ray scattering measurements were performed on the SWING beamline at the SOLEIL synchrotron. Two sample-to-detector distances (1 and $6 \mathrm{~m})$ were used with a wavelength of $1.03 \AA$. This setup allowed access to a momentum transfer q range of $2.0 \times 10^{-3}-$ $0.7 \AA^{-1}$. Measurements were also performed on the XEUSS 2.0 spectrometer from Xenocs (CEA-LIONS/LLB, Saclay, France). Two sample-to-detector distances (33 and $249 \mathrm{~cm}$ ) were used with a wavelength of $1.54 \AA$ (Cu X-ray source). This setup allowed access to a momentum 
transfer range of $4.5 \times 10^{-3}-0.5 \AA^{-1}$. Measurements were performed on the suspensions exiegeptide Online for the three settled samples (Figure SI 1) for which the experiments were carried out on the precipitate. All scattering curves were rescaled as a function of the apparent concentration in the high q range.

The cluster fractal model described in Guénet et al. ${ }^{13}$ was used to analyse the SAXS curves. For centrosymmetric nanoparticles dispersed in a continuous solvent, here water, the scattered intensity is described by the following equation (eq. 1):

$$
\mathrm{I}(\mathrm{q})=\varphi \cdot V \cdot \Delta \rho^{2} \cdot \mathrm{P}(\mathrm{q}) \cdot \mathrm{S}(\mathrm{q})
$$

where $\varphi$ is the volume fraction, $\mathrm{V}$ is the volume of the scattered entities, $\Delta \rho^{2}$ is the contrast term, $\mathrm{P}(\mathrm{q})$ is the form factor and $\mathrm{S}(\mathrm{q})$ is the structure factor. The model was established considering that the samples are composed of Fe spherical poly-dispersed primary beads (FePB). Part of these PB is organized as Fe primary aggregates (Fe-PA) described by a form factor according to a finite number of $\mathrm{PB}$ and a fractal dimension. These Fe-PA self-assembled as a third aggregation level, i.e. the Fe secondary aggregates (Fe-SA).

\subsection{SANS and VSANS acquisition and analysis}

The neutron scattering length density (SLD) of $\mathrm{H}_{2} \mathrm{O}$ is $\mathrm{SLD}_{\mathrm{H}_{2} \mathrm{O}}=-0.56 \times 10^{10} \mathrm{~cm}^{-2}$ while $\mathrm{SLD}_{\mathrm{D}_{2} \mathrm{O}}$ $=6.4 \times 10^{10} \mathrm{~cm}^{-2}$. Considering $\operatorname{SLD}_{\mathrm{OM}}=1.18 \times 10^{10} \mathrm{~cm}^{-2}$ and $\operatorname{SLD}_{\mathrm{Fe}}=6.05 \times 10^{10} \mathrm{~cm}^{-2}{ }^{13}, \mathrm{Fe}-\mathrm{Ca}-$ OM aggregates were synthesized in $\mathrm{D}_{2} \mathrm{O}$ to match the Fe contribution to the neutron scattering and to only characterize the OM part. We completed the SANS investigation with a second intermediate contrast at $50 / 50 \% \mathrm{H}_{2} \mathrm{O} / \mathrm{D}_{2} \mathrm{O}$ to see whether we can identify a local contribution of the OM scattering signal. Small-angle neutron scattering (SANS) experiments were performed on the PA20 beamline (LLB, Saclay, France). Three sample-to-detector distances (2, 8 and $18 \mathrm{~m}$ ) were used with a wavelength of $6 \AA$. This setup allowed access to a momentum transfer range of $2.1 \times 10^{-3}-0.3 \AA^{-1}$. SANS measurements were also performed on KWS-2 diffractometers ${ }^{45}$ operated by the Jülich Centre for Neutron Science (JCNS) at the Heinz Maier- 
Leibnitz Zentrum (MLZ) in Garching, Germany. Using a sample-to-detector distance of Niqu fricle Online and $7.6 \mathrm{~m}$ with a wavelength of $7 \AA(\Delta \lambda / \lambda=10 \%)$ and a sample-to-detector distance of $19.5 \mathrm{~m}$ with a wavelength of $10 \AA(\Delta \lambda / \lambda=10 \%)$ : the q-range $1.9 \times 10^{-3}-4.5 \times 10^{-1} \AA^{-1}$ was covered. Very small-angle neutron scattering (VSANS) experiments were carried out with KWS-3 diffractometers ${ }^{46}$ operated by the JCNS at the MLZ. Using a neutron wavelength of $12.8 \AA$ with $\Delta \lambda / \lambda=17 \%$ and a sample to detector distance of $0.51 \mathrm{~m}, 1.25 \mathrm{~m}$ and $9.2 \mathrm{~m}$, a q-range from approximately $2.1 \times 10^{-4}-5.0 \times 10^{-2} \AA^{-1}$ was covered. Like for SAXS, SANS measurements were performed on suspensions except for the three settled samples (Figure SI 1) for which experiments were carried out on the precipitate. All scattering curves were rescaled to the apparent concentration in the high q range. Data were corrected and calibrated using the Pasinet and QtiKWS softwares.

SANS curves were fitted using the SasView software with the following Guinier-Porod equation ${ }^{47}$ (eq. 2):

$$
I(q)=\left\{\begin{array}{c}
\frac{G}{q^{s}} \exp \left(\frac{-q^{2} R_{g}^{2}}{3-s}\right) \quad \text { for } q<q_{\text {cut }- \text { off }} \\
\frac{D}{q^{\alpha}} \text { for } q>q_{\text {cut }- \text { off }}
\end{array}\right.
$$

where $\mathrm{G}$ and $\mathrm{D}$ are scaling factors for the Guinier and Porod domains respectively, $\mathrm{R}_{\mathrm{g}}$ is the gyration radius that corresponds to a typical size of the system, $\mathrm{s}$ is a parameter illustrating the nonspherical form of the object ( $\mathrm{s}=0$ for a sphere, $\mathrm{s}=1$ for rods and $\mathrm{s}=2$ for lamellae) and $\alpha$ is the slope of the curve related to the fractal dimension $\left(D_{f}\right)$ of the object. The $q_{\text {cut-off }}$ defines the limit between the Guinier and the Porod regime.

\subsection{Imaging}

For the TEM measurements, $5 \mu \mathrm{L}$ of the samples were dropped on a copper grid with a lacy carbon coated film (Agar scientific, AGS166-3) and then dried at room temperature. Transmission electron microscopy images were recorded using a JEOLL 100CXII instrument at $100 \mathrm{kV}$ (THEMIS Analytical Facility, University of Rennes 1) equipped with an X-ray 
energy dispersive spectroscopy (XEDS) detector (Kevex detector with an ultrathin wind wow For the cryo-TEM measurements, samples were vitrified using a Leica EM GP immersion under controlled humidity and temperature ${ }^{48}$. Samples were deposited on glow-discharged electron microscope grids followed by blotting and vitrification by rapid freezing in liquid ethane ($184^{\circ} \mathrm{C}$ ). Grids were transferred to a single-axis cryo-holder (model 626, Gatan) and were observed using a $200 \mathrm{kV}$ electron microscope (Tecnai G2 T20 Sphera, FEI) equipped with a 4k $\times$ 4k CCD camera (model USC 4000, Gatan). Micrographs were acquired under low electron doses using the camera in binning mode 1 and at a nominal magnification of 50,000x. For the cryo-TXM measurements, samples were frozen using a Leica EM GP immersion freezer. The environmental chamber was kept at $20^{\circ} \mathrm{C}$ with $80 \%$ humidity. Four $\mu \mathrm{L}$ of the sample were dropped on a hydrophilized (air plasma treated using Henniker HPT-100 plasma treatment) carbon coated copper grid (Quantifoil R2/2 type grid). The grid was blotted with ${ }^{\circ} 1$ Whatman filter paper prior to freezing and then automatically plunged into liquid ethane. The samples were stored in liquid nitrogen until further use. The cryo-TXM images were recorded at the full field transmission soft X-ray microscope installed at the MISTRAL beamline ${ }^{49}$ of the ALBA synchrotron. A capillary condenser lens after the monochromator exit slit focuses the radiation to the sample. After the sample, a Fresnel zone plate with outermost zone width of $25 \mathrm{~nm}$ was used as objective lens to record a magnified image on a direct illumination CCD detector (Pixis XO by Princeton Instruments with $1024 \times 1024$ pixels and $13 \mu \mathrm{m}$ pixel size). The spatial resolution of the system is limited by the objective lens and was estimated to be $23 \mathrm{~nm}$ half pitch at $520 \mathrm{eV}$ using a Siemens star pattern with $30 \mathrm{~nm}$ smallest features ${ }^{50}$. The magnification used for the transmission image was $\times 1300$, corresponding to an effective pixel size of $10 \mathrm{~nm}$. Twenty images with an exposure time of 3 seconds each were acquired and then averaged. The average transmitted intensity I and the corresponding Flat Field I0 (i.e. the incident intensity on the sample) were used to obtain the transmission $\mathrm{T}$, related to the linear absorption coefficient 
of the sample by the Beer-Lambert law. The energy was set to $520 \mathrm{eV}$ to maximize the contitrastitcle Online between water and carbon, calcium and iron rich regions of the imaged suspension.

\section{$\underline{\text { Results and discussion }}$}

\section{Iron speciation within aggregates}

Fe speciation within the aggregates was studied by XAS at Fe K-edge. The XANES spectra (Figure SI 2) are similar and representative of Fe(III) in an octahedral symmetry ${ }^{51}$. All EXAFS spectra exhibit a maximum of amplitude at $6.3 \AA^{-1}$ (Figure 1). Fe(II) and Fe(III)-oligomer spectra exhibit a damping shape that is close to monotonous. The oscillations of the Fe(II) spectra are shifted to low photoelectron wavevector, k, values as compared to $\mathrm{Fe}(\mathrm{III})$ species. Iron(III)-Np and Fh exhibit a shoulder at $5.1 \AA^{-1}$ and an oscillation at $7.5 \AA^{-1}$ that are more intense for Fh than Fe(III)-Np (Figure 1a). The Lp spectrum is well-structured with a shoulder at $4.7 \AA^{-1}$, a strong oscillation at $7.2 \AA^{-1}$ and a smaller one at $7.9 \AA^{-1}$. For the Fe-OM-Ca aggregates, the oscillations occurred at the same k values as the Fe(III) references evidencing the presence of $\mathrm{Fe}(\mathrm{III})$. More precisely, two different behaviours can be observed depending on the $\mathrm{Fe} / \mathrm{OC}$ ratio. Spectra for $\mathrm{Fe} / \mathrm{OC}=0.02$ exhibit a monotonous shape except at $7.5 \AA^{-1}$ where a shoulder occurs (Figure 1b). Samples formed at $\mathrm{Fe} / \mathrm{OC}=0.05$ and $\mathrm{Fe} / \mathrm{OC}=0.08$ exhibit more structured EXAFS spectra with an additional shoulder at $5.1 \AA^{-1}$ and a pronounced shoulder at $7.4 \AA^{-1}$ (Figure 1c and d).

Guénet et al. ${ }^{2}$ demonstrated that nano-Lp coexist with small Fe-clusters bound to $\mathrm{OM}$ in riparian wetland soils. Similar results were demonstrated by Thomas Arrigo et al. ${ }^{6}$ who provided evidence of Fh and Lp occurrence in OM-rich environmental systems. Moreover, Vantelon et $a l .{ }^{14}$ demonstrated that within $\mathrm{Fe}(\mathrm{III})-\mathrm{OM}$ aggregates for $\mathrm{Fe} / \mathrm{OC}=0.08, \mathrm{Fe}(\mathrm{III})$-oligomers and $\mathrm{Fe}(\mathrm{III})-\mathrm{Np}$ occurred together. Linear combination fittings were performed on the EXAFS spectra of the Fe-OM-Ca aggregates using the signal of Fe(II), Fe(III)-oligomers, Fe(III)-Np, Fh and Lp. Only Fe(III)-oligomers and Fe(III)-Np EXAFS signals were necessary to reproduce 


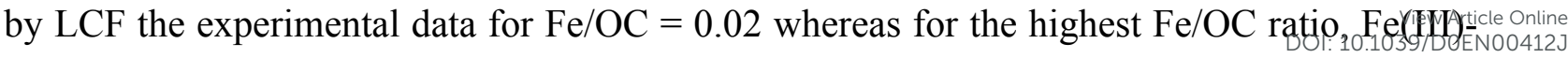
oligomers, Fe(III)-Np and Fh EXAFS signals were needed. If they exist, Fe(II) and Lp amount were below the detection limit (Figure 1 and Table SI 1). Several studies similarly demonstrated that with fulvic or humic acids, Fe(II) oxidation-hydrolysis did not produce $\mathrm{Lp}^{14,17,52}$. This discrepancy regarding the occurrence of Lp could be explained by the variability in the physicochemical conditions prevailing during aggregate formation.

(a)

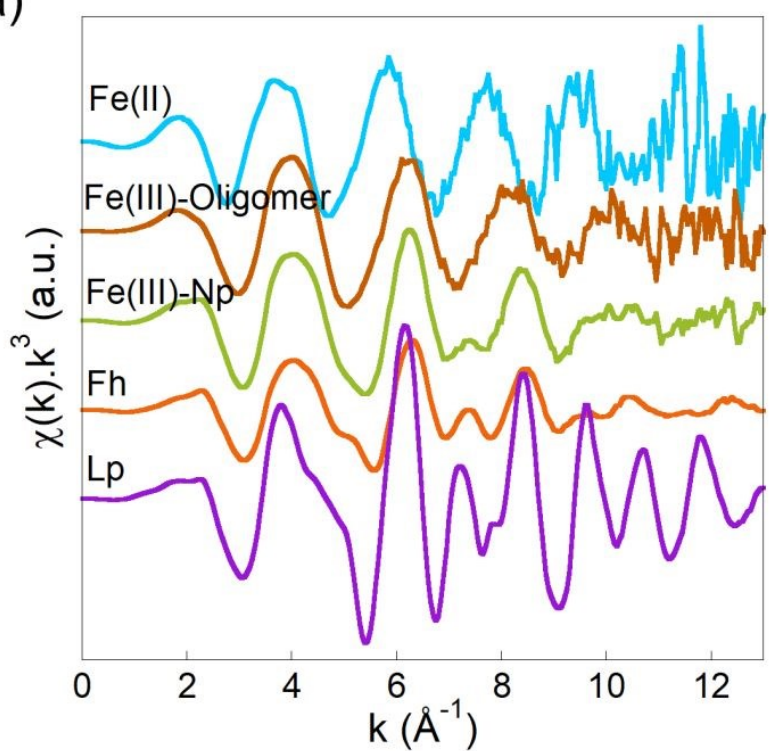

(c)

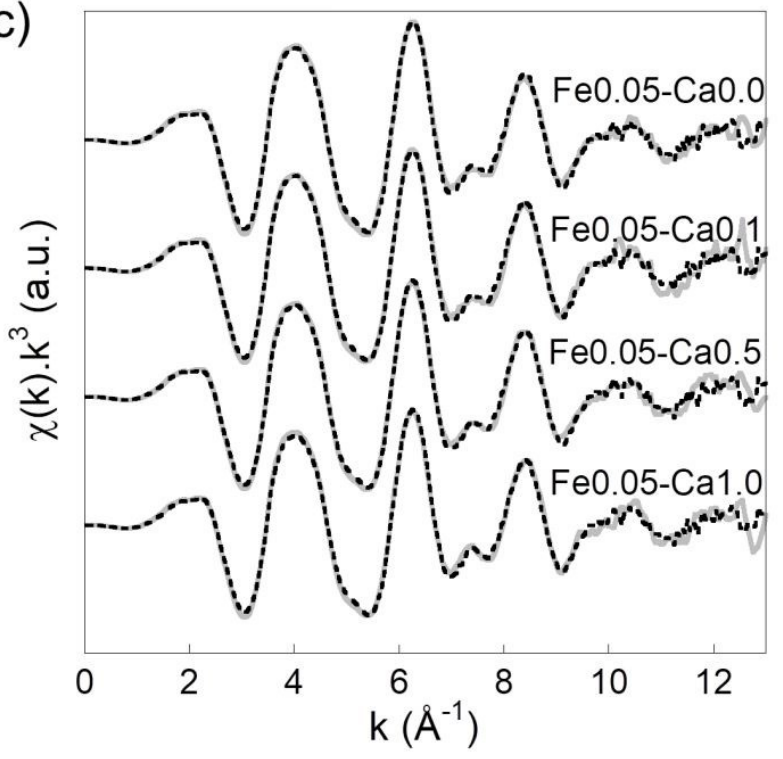

(b)

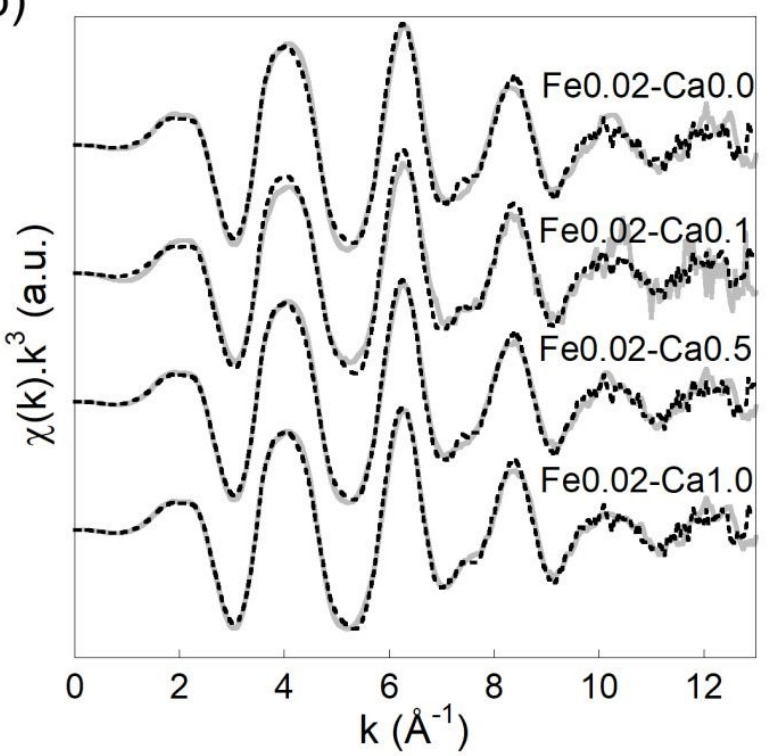

(d)

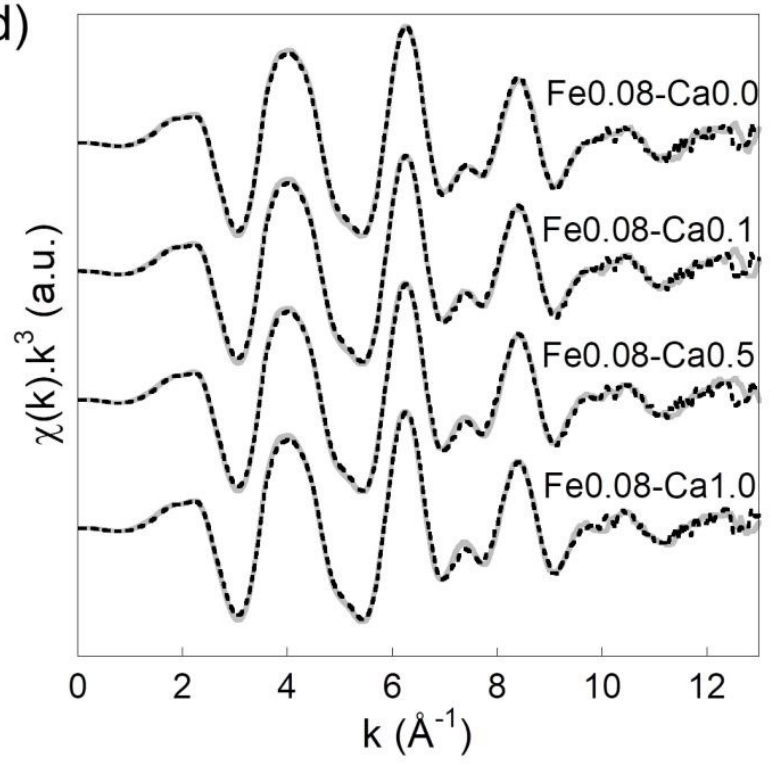

Figure 1 - Iron K-edge EXAFS spectra of (a) references used for LCF and samples at (b) $\mathrm{Fe} / \mathrm{OC}=0.02$, (c) $\mathrm{Fe} / \mathrm{OC}=0.05$ and (d) $\mathrm{Fe} / \mathrm{OC}=0.08$. Solid lines are experimental data and dotted lines are the LCF results.

For $\mathrm{Fe} / \mathrm{OC}=0.02$, and $\mathrm{Ca} / \mathrm{Fe}=0.0$ and 0.1 , the EXAFS signal features at 5.1 and $7.4 \AA^{-1}$ are 
not perfectly reproduced by LCF. For Fe/OC $=0.08, \mathrm{Fe}(\mathrm{III})$-oligomers are describedidwaricle Online tetramers bound to $\mathrm{OM}^{14}$. However, Vilgé-Ritter et al. ${ }^{53}$ and Mikutta et al. ${ }^{11}$ described Fe(III)oligomers as trimers for $\mathrm{Fe} / \mathrm{OC}=0.02$ and 0.004 respectively. For $\mathrm{Fe} / \mathrm{OC}=0.02, \mathrm{Fe}(\mathrm{III})$ monomers bound to OM were also reported by Karlsson and Persson ${ }^{19}$. The tiny discrepancy observed between the data and LCF can therefore be explained by the difference in the Fe/OC ratio for the references used for fitting. The Fe(III)-Np signal may also be slightly different than the one used for the fit due to a particle size effect. In any case, for $\mathrm{Fe} / \mathrm{OC}=0.02, \mathrm{Fe}$ occurs at around $30 \%$ as $\mathrm{Fe}(\mathrm{III})$-oligomers and $70 \%$ as $\mathrm{Fe}(\mathrm{III})-\mathrm{Np}$ irrespective of the $\mathrm{Ca} / \mathrm{Fe}$ ratio (Figure 2). For $\mathrm{Fe} / \mathrm{OC}=0.05$ and $0.08, \mathrm{Fe}$ is organized as $\mathrm{Fe}(\mathrm{III})$-oligomers, Fe(III)-Np and Fh. With increasing $\mathrm{Fe} / \mathrm{OC}$ and $\mathrm{Ca} / \mathrm{Fe}, \mathrm{Fe}(\mathrm{III})-\mathrm{Np}$ remains constant (around 55\%) whereas $\mathrm{Fe}(\mathrm{III})-$ oligomers amount decrease in favour of Fh until reaching a steady state at $13 \% \mathrm{Fe}(\mathrm{III})-$ oligomers, $34 \% \mathrm{Fh}$ and $53 \% \mathrm{Fe}(\mathrm{III})-\mathrm{Np}$ for $\mathrm{Fe} / \mathrm{OC}=0.08$ and $\mathrm{Ca} / \mathrm{Fe} \geq 0.1$. These results are in agreement with Chen et al. ${ }^{18}$. By co-precipitating $\mathrm{Fe}(\mathrm{III})$ with $\mathrm{OM}$ at $\mathrm{Fe} / \mathrm{OC}=0.44$, they provided evidence that $72 \%$ of Fe was organized as Fh and $28 \%$ as so-called "insoluble Fe(III)OM" species (described by van Schaik et al. ${ }^{25}$ as Fe trimers bound to OM).

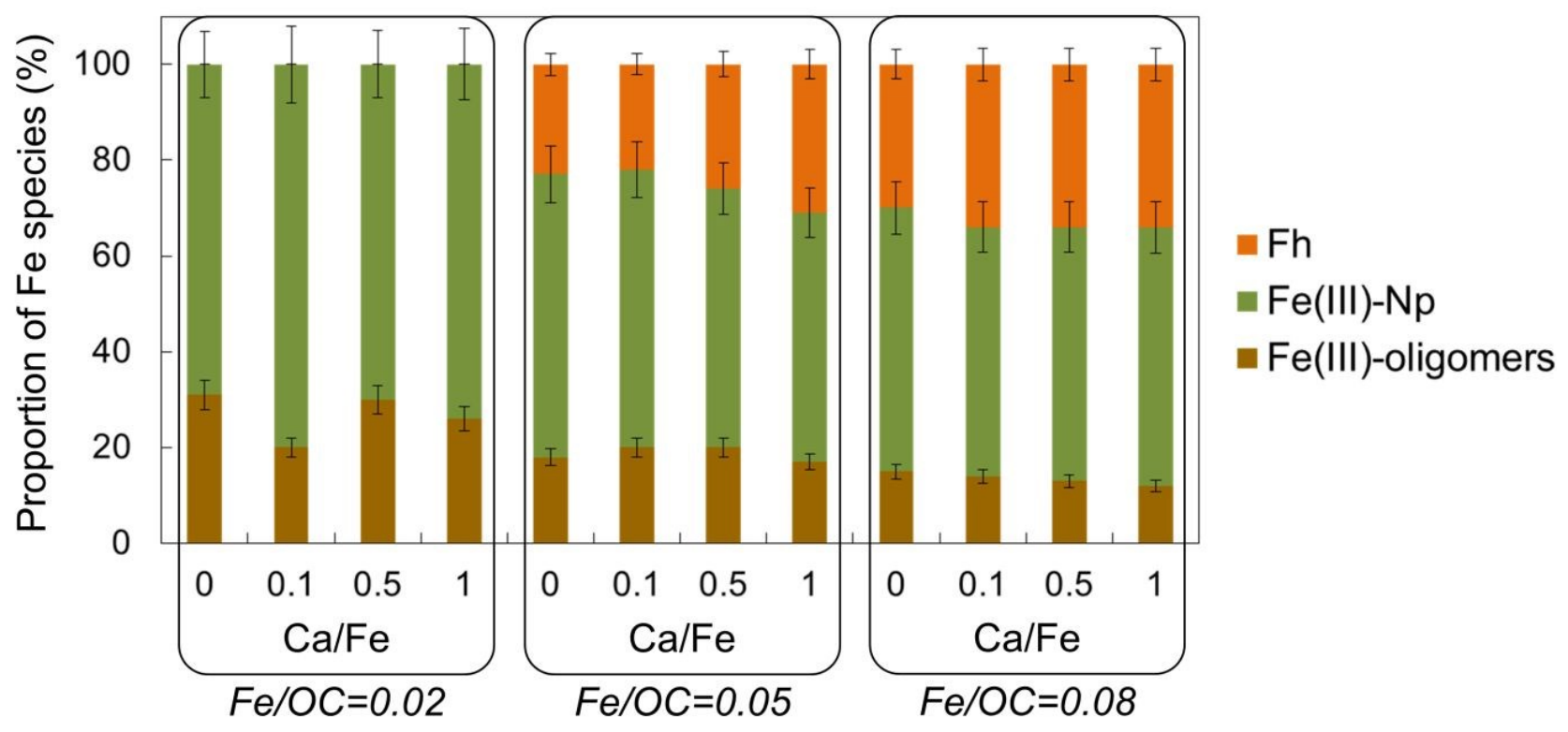

Figure 2 - Proportion of Fe(III)-oligomers (brown), Fe(III)-Np (green) and Fh (orange) determined by LCF of the EXAFS data shown in Figure 1. 
SAXS measurements are used to investigate the Fe part of Fe-OM-Ca aggregates (Figure 3).

The X-ray contrast only depends on the electronic density of the element, which is significantly larger for Fe as compared to OM (the OM part is thus invisible in the scattering signal). The high q part of the scattering curve corresponds to the form factor of Fe primary beads (Fe-PB) that can be modelled with a spherical form factor with a radius equal to $0.8 \mathrm{~nm}$. These Fe-PB are consistent with the coherent scattering domains of Fh described by Michel et al. ${ }^{54}$. All curves exhibit a shoulder between $10^{-2}$ and $10^{-1} \AA^{-1}$ indicating a characteristic size of Fe, corresponding to Fe primary aggregates (Fe-PA) made of Fe-PB. This shoulder shifts to the lowest $\mathrm{q}$ with the increasing $\mathrm{Ca} / \mathrm{Fe}$ ratio, indicating that the size of the Fe-PA increases. Two different behaviours of the inflexion shape can be observed depending on the Fe/OC ratio. For $\mathrm{Fe} / \mathrm{OC}=0.02$, the inflexion is lower without $\mathrm{Ca}$ than with $\mathrm{Ca}$. By contrast, the increasing $\mathrm{Ca} / \mathrm{Fe}$ ratio leads to the attenuation of the inflexion for $\mathrm{Fe} / \mathrm{OC}=0.05$ and 0.08 . At low $\mathrm{q}$, the increase in intensity indicates the aggregation of Fe-PA as larger objects, i.e. Fe secondary aggregates (Fe-SA) for which the size cannot be determined given the limited q range. 
(a)

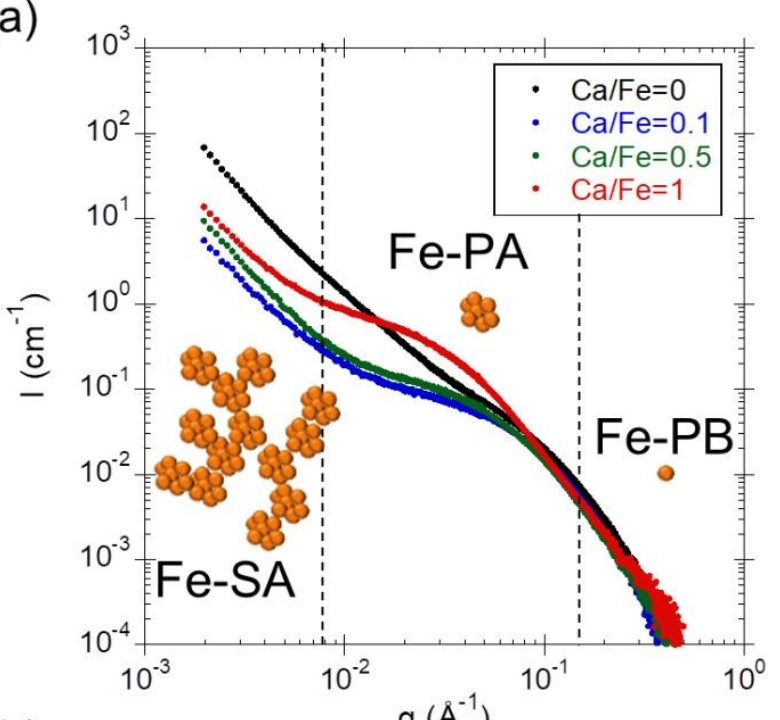

(b)

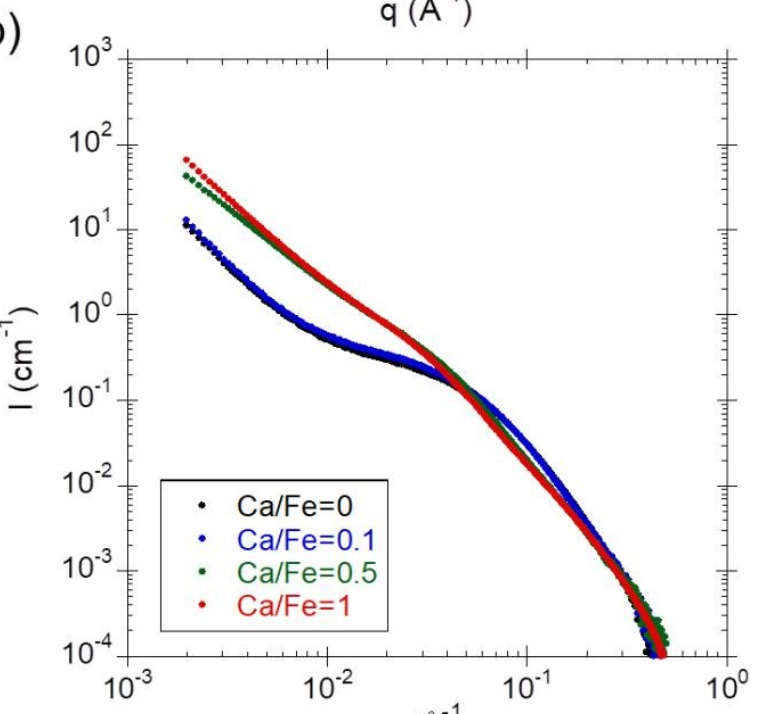

(c)

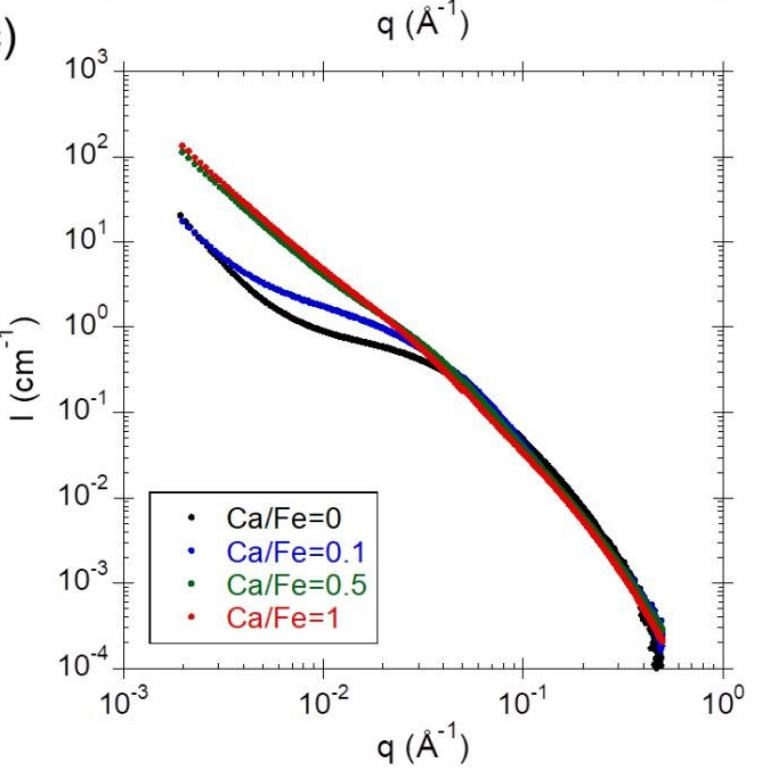

Figure 3 - SAXS curves for samples with (a) $\mathrm{Fe} / \mathrm{OC}=0.02$, (b) $\mathrm{Fe} / \mathrm{OC}=0.05$ and (c) $\mathrm{Fe} / \mathrm{OC}=0.08$. In (a) $\mathrm{Fe}$ $\mathrm{PB}, \mathrm{Fe}-\mathrm{PA}$ and Fe-SA are represented in their corresponding scattering domain. 
At intermediate q, the form factor of Fe-PA was extracted to determine their radius (Figuriar SIcle Online 4, Table SI 2 and Figure 4) which increases with the increasing Fe/OC ratio as demonstrated by Guénet et al. ${ }^{13}$. Furthermore, the Fe-PA size also increases with the increasing $\mathrm{Ca} / \mathrm{Fe}$ ratio while their morphology remains constant as highlighted by the Fe-PA fractal dimension which is $\square 2.4$ irrespective of the $\mathrm{Fe} / \mathrm{OC}$ or $\mathrm{Ca} / \mathrm{Fe}$ ratio (Table SI 2).

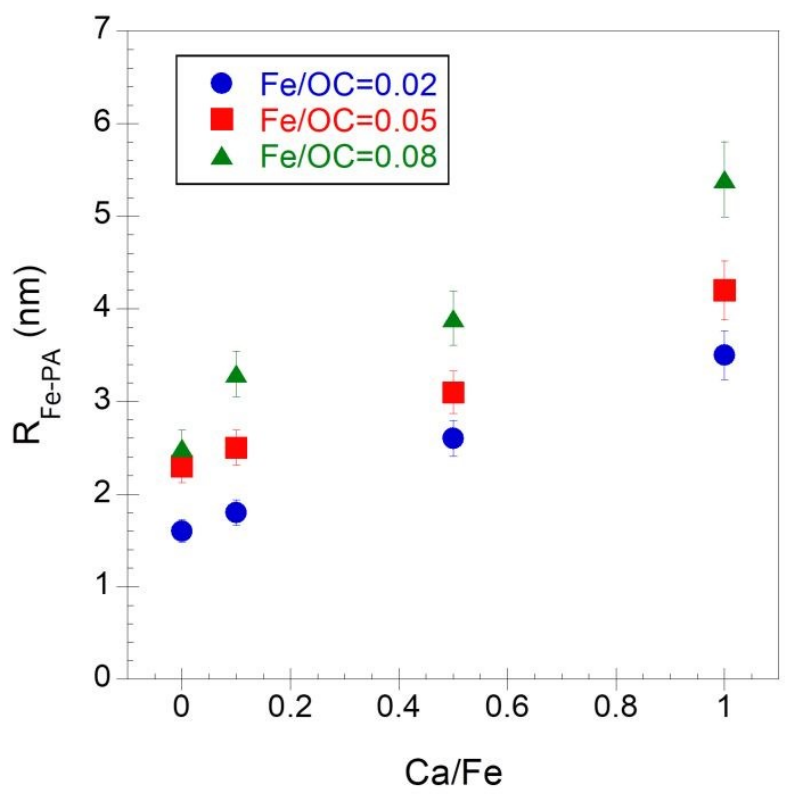

Figure 4 - Variations in the radius of the $\mathrm{Fe}$ primary aggregates relative to $\mathrm{Ca} / \mathrm{Fe}$ for $\mathrm{Fe} / \mathrm{OC}=0.02$ (blue circles), 0.05 (red squares) and 0.08 (green triangles).

The total structure factor $\left(\mathrm{S}_{\mathrm{T}}(\mathrm{q})\right)$ can be extracted by dividing the total scattering intensity by the form factor of Fe-PA (Figure SI 5). The increase of the $\mathrm{S}_{\mathrm{T}}(\mathrm{q})$ intensity as a power law in the range $8 \times 10^{-2}-1 \times 10^{-3} \AA^{-1}$ is relevant to the Fe-SA contribution. The shoulder observed between $3 \times 10^{-1}$ and $7 \times 10^{-2} \AA^{-1}$ in $\mathrm{S}_{\mathrm{T}}(\mathrm{q})$ indicates interactions between the Fe-PA inside the Fe-SA. This shoulder can be used to calculate the centre-to-centre distance $\mathrm{d}_{0}$ between Fe-PA within Fe-SA (Table 2 and Figure SI 5). For samples exhibiting the lowest Ca contents, $\mathrm{d}_{0}$ increases with increasing $\mathrm{Fe} / \mathrm{OC}$ and $\mathrm{Ca} / \mathrm{Fe}$ ratios as a response to the increase in $\mathrm{Fe}-\mathrm{PA}$ size since the $\mathrm{d}_{0}$ values range from $2 \times \mathrm{R}_{\mathrm{PA}}$ to $2.8 \times \mathrm{R}_{\mathrm{PA}}$. However, the key result is observed for the four samples exhibiting the highest $\mathrm{Ca}$ contents for which no peak occurred, suggesting a loss of correlation between Fe-PA in response to a longer distance between Fe-PA and/or a larger $\mathrm{d}_{0}$ dispersity. 
As a result, the presence of $\mathrm{Ca}$ leads to a long range correlation between the $\mathrm{Fe}_{\mathrm{D}}$-pritivisufficle Online aggregates.

Table 2 - Values of the centre-to-centre distance $\mathrm{d}_{0}$ between Fe-PA. A '-' is reported when the correlation peak of Fe-PA did not occur, indicating an increase in the distance between Fe-PA.

\begin{tabular}{|c|c|c|c|c|c|}
\hline \multirow{2}{*}{\multicolumn{2}{|c|}{ d0 (nm) }} & \multirow{2}{*}{$\begin{array}{r}\mathrm{Ca} / \mathrm{Fe} \\
0.0\end{array}$} & \multirow[b]{2}{*}{0.1} & \multirow[b]{2}{*}{0.5} & \multirow[b]{2}{*}{1.0} \\
\hline & & & & & \\
\hline $\mathrm{Fe} / \mathrm{OC}$ & 0.02 & 4.4 & 4.9 & 6.0 & 6.5 \\
\hline & 0.05 & 5.5 & 5.9 & - & - \\
\hline & 0.08 & 4.7 & 7.2 & - & - \\
\hline
\end{tabular}

At $\mathrm{Fe} / \mathrm{OC}=0.05$, TEM observations showed black spherical entities (Figure 5). The XEDS analysis revealed the presence of Fe indicating that these black dots are Fe particles, as previously observed for synthetic and natural samples ${ }^{3,13,55}$. Their compact spherical and nanometric size (between 2 and $6 \mathrm{~nm}$ ) is consistent with Fe-PA identified by SAXS. Moreover, their size increases with the increasing $\mathrm{Ca} / \mathrm{Fe}$ ratio from $\square 2 \mathrm{~nm}$ for $\mathrm{Fe} 0.05-\mathrm{Ca} 0.0$ and $\mathrm{Fe} 0.05$ Ca0.1 (Figure 5a and b) to $\square 5.5 \mathrm{~nm}$ for Fe0.05-Ca1.0 (Figure 5d), confirming the SAXS results. 
(a)

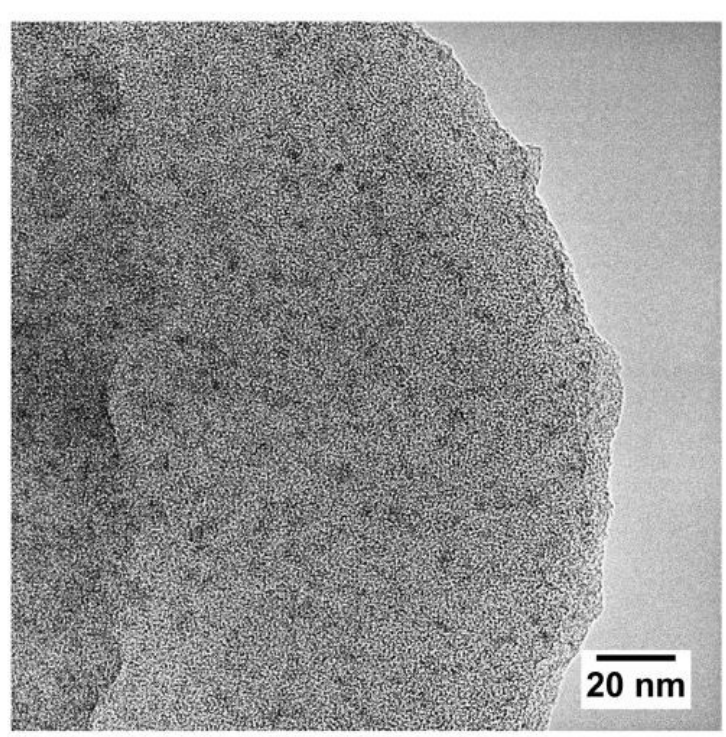

(c)

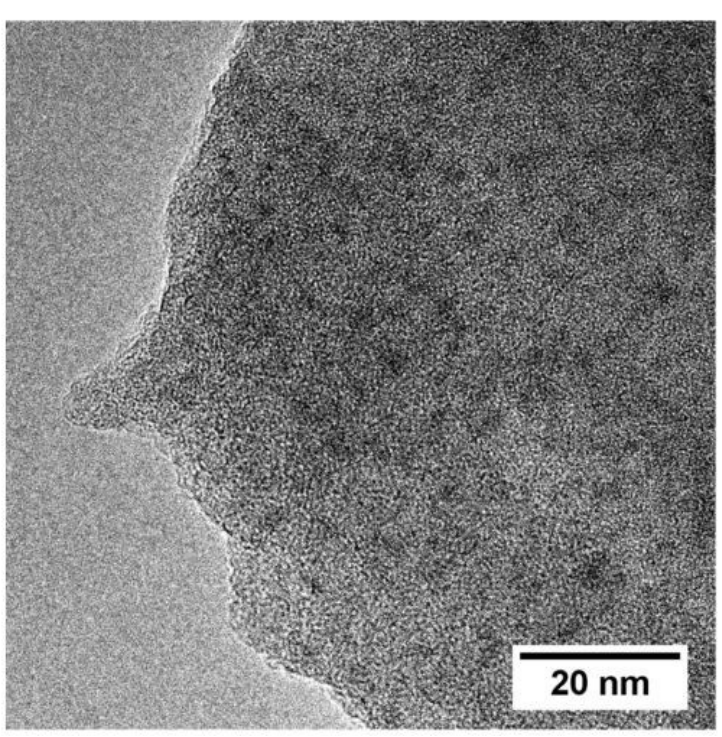

(b)

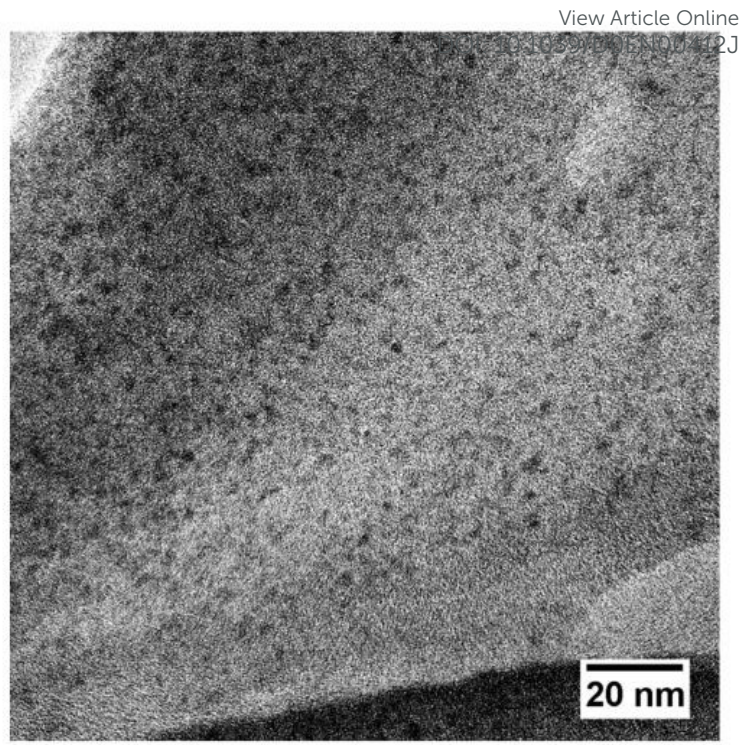

(d)

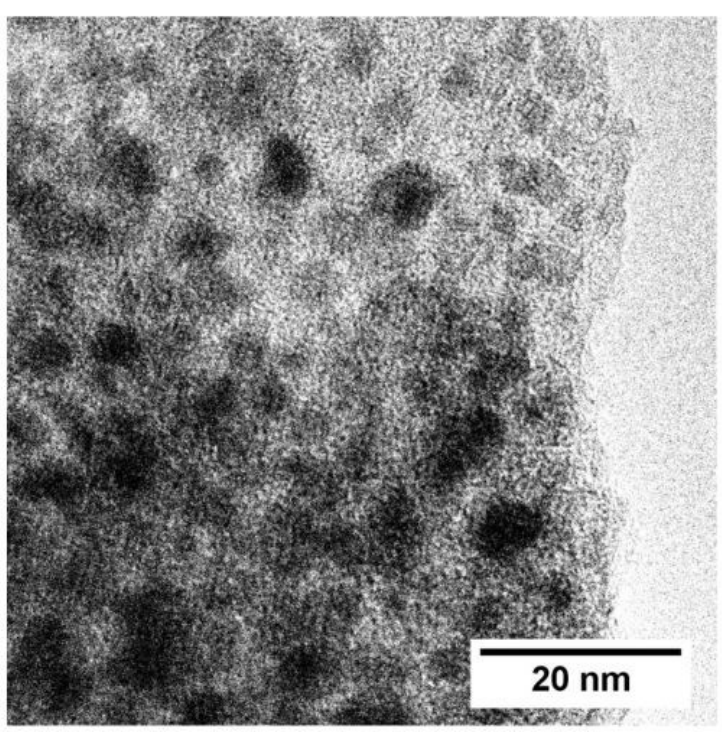

Figure 5 - Transmission electron microscopy images of the aggregates for $\mathrm{Fe} / \mathrm{OC}=0.05$ and (a) $\mathrm{Ca} / \mathrm{Fe} 0$, (b) $\mathrm{Ca} / \mathrm{Fe} 0.1,(\mathrm{c}) \mathrm{Ca} / \mathrm{Fe} 0.5$ and (d) $\mathrm{Ca} / \mathrm{Fe} 1$. The grey scales are arbitrary.

\section{Structural arrangement of OM in the aggregates}

SANS measurements with a $100 \% \mathrm{D}_{2} \mathrm{O}$ contrast allowed to match the iron scattering contribution to the signal and to access the OM part of the aggregates. For SANS curves with $100 \% \mathrm{D}_{2} \mathrm{O}$ contrast (Figure 6a,b,c), the inflexion observed for $\mathrm{q}<10^{-3} \AA^{-1}$ suggests a typical size for the OM aggregates. This inflexion shifts to the lower q when increasing $\mathrm{Ca} / \mathrm{Fe}$ ratio suggesting an increase of the OM size. However, these curves exhibit the same slope in the q domain between $10^{-3}$ and $10^{-1} \AA^{-1}$ irrespective to the $\mathrm{Fe} / \mathrm{OC}$ or the $\mathrm{Ca} / \mathrm{Fe}$ ratio, suggesting no local scattering contribution from OM phases. To enforce this observation, SANS curves with 
$50 / 50 \% \mathrm{H}_{2} \mathrm{O} / \mathrm{D}_{2} \mathrm{O}$ contrast were measured (Figure 6d,e,f). At this specific contrast, bothiethedecle Online contribution of $\mathrm{OM}$ and the Fe is visible. For $\mathrm{q}>10^{-2} \AA^{-1}$, this contrast can also be used to test if another OM organization (e.g. smaller molecules than the OM aggregates) could contribute to the signal. In the q domain between $10^{-3}$ and $10^{-2} \AA^{-1}$, no differences were observed between samples as all the curves exhibit the same slope. In the q domain between $10^{-2}$ and $10^{-1} \AA^{-1}$, an inflexion occurs for samples with the highest $\mathrm{Ca} / \mathrm{Fe}$ ratios, suggesting a variation in the local organization. In this range, the SANS and SAXS curves can be superimposed showing an identical signal provided mainly by Fe-PA (Figure SI 6). This result confirms that no local modification of $\mathrm{OM}$ occurs as its local scattering contribution is the same irrespective of the $\mathrm{Fe} / \mathrm{OC}$ and $\mathrm{Ca} / \mathrm{Fe}$ ratios. 
(a)

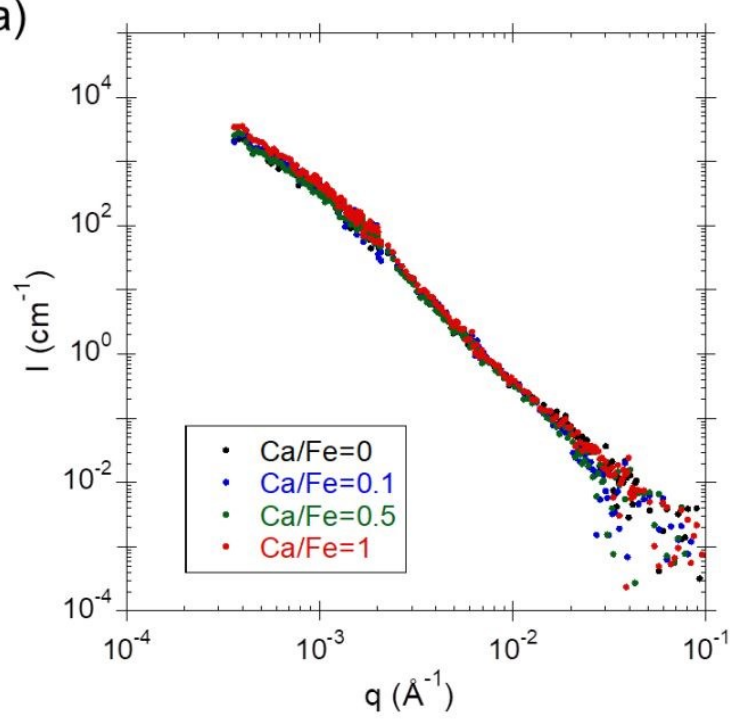

(b)

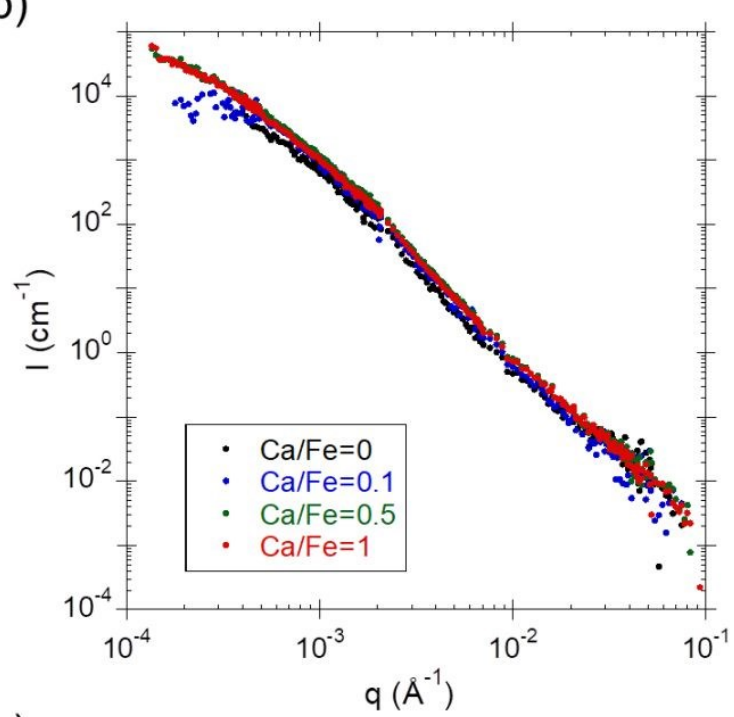

(c)

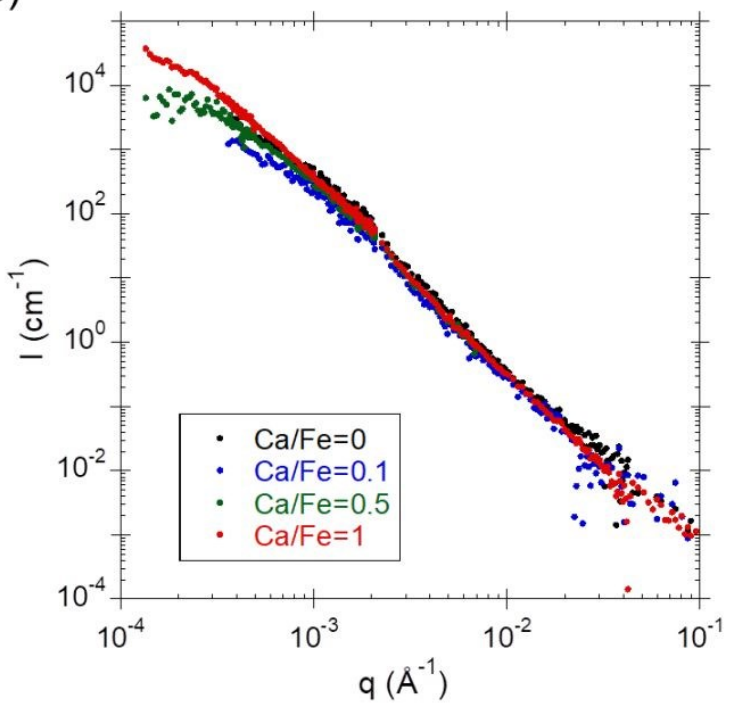

(d)

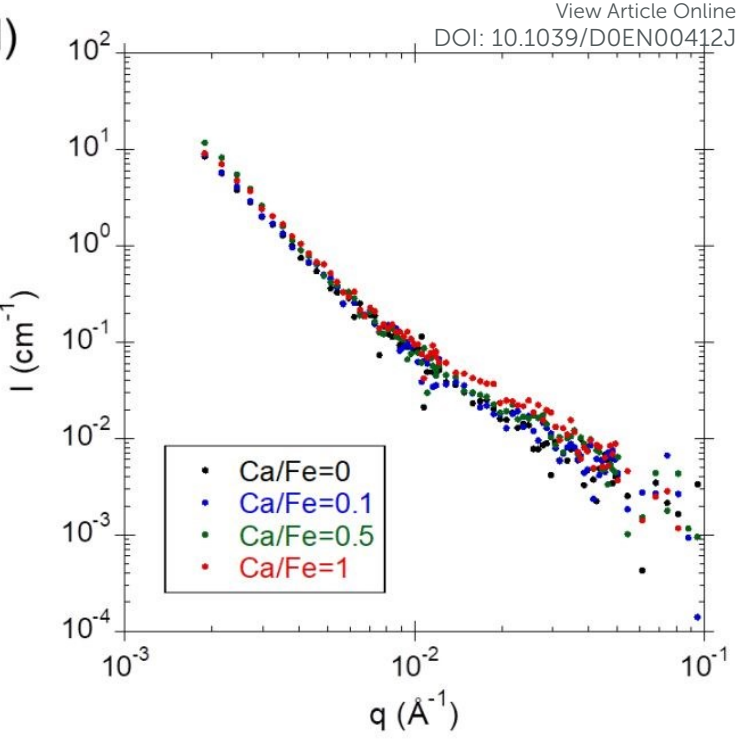

(e)

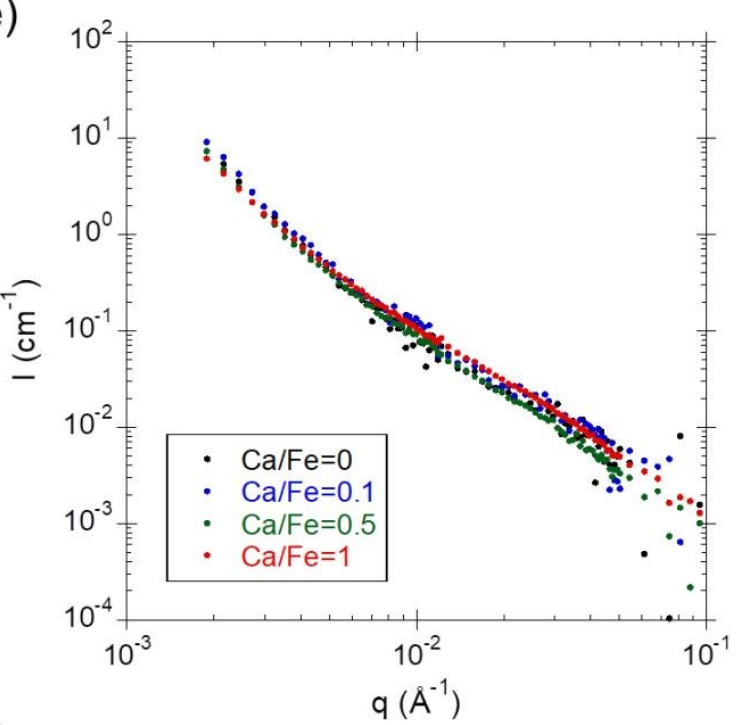

(f)

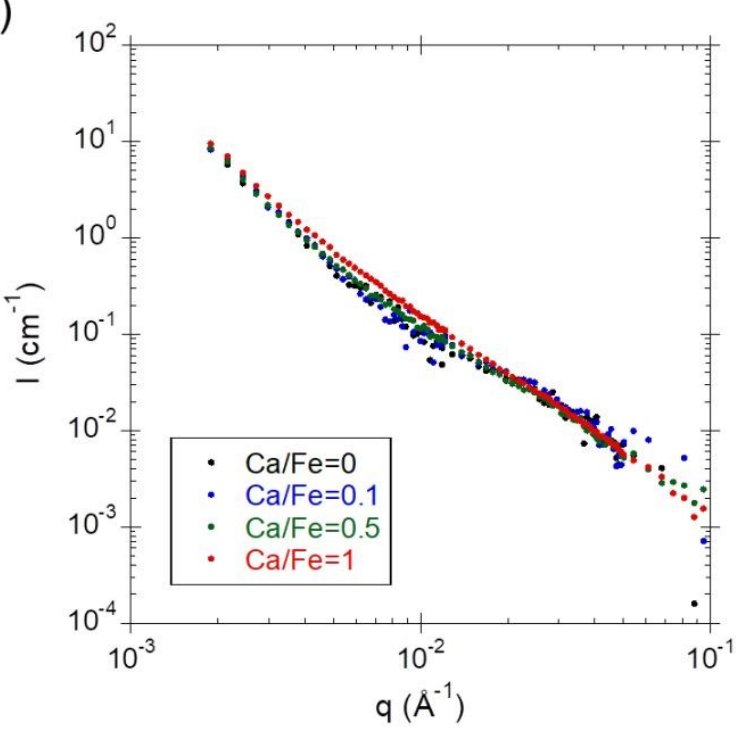

Figure 6 - SANS curves with $100 \% \mathrm{D}_{2} \mathrm{O}$ contrast for samples with a Fe/OC ratio of (a) 0.02 , (b) 0.05 and (c) 0.08 , and with contrast at $50 / 50 \% \mathrm{H}_{2} \mathrm{O} / \mathrm{D}_{2} \mathrm{O}$ for samples with a $\mathrm{Fe} / \mathrm{OC}$ ratio of (d) 0.02 , (e) 0.05 and (f) 0.08 . 
All $100 \% \mathrm{D}_{2} \mathrm{O}$ contrast curves were fitted with the Guinier-Porod equation (eq. 2)(Figuriew SIcle Online 7). The parameters used are reported in Table SI 3. All curves exhibit a fractal dimension, $D_{f}$ around 2.8, consistent with previous observations on synthetic samples ${ }^{13}$ and natural samples ${ }^{56,57}$. However, several studies reported a $D_{f}$ value for $O M$ between 2 and $2.5^{58-60}$. Osterberg and Mortensen ${ }^{59}$ and Guénet et al. ${ }^{13}$, applied a Guinier model on natural and synthetic aggregates at $\mathrm{Fe} / \mathrm{OC}=0$ or 0.01 , respectively to obtain a gyration radius for $\mathrm{OM}$ from $30 \mathrm{~nm}^{59}$ to approximately $100 \mathrm{~nm}^{13}$. The Guinier plateau tends to disappear with the increasing Fe/OC ratio in Guénet et al. ${ }^{13}$ and Osterberg and Mortensen ${ }^{59}$. However, Diallo et al. ${ }^{58}$ did not observe the same trend for natural aggregates. In our work, VSANS was used to reach lower q, to provide better evidence of a Guinier plateau and to calculate the typical OM size (Figure 7 and Table SI 3). The results showed an increase in $\mathrm{OM}$ size with the increasing $\mathrm{Ca} / \mathrm{Fe}$ ratios without any local reorganization of the OM phase.

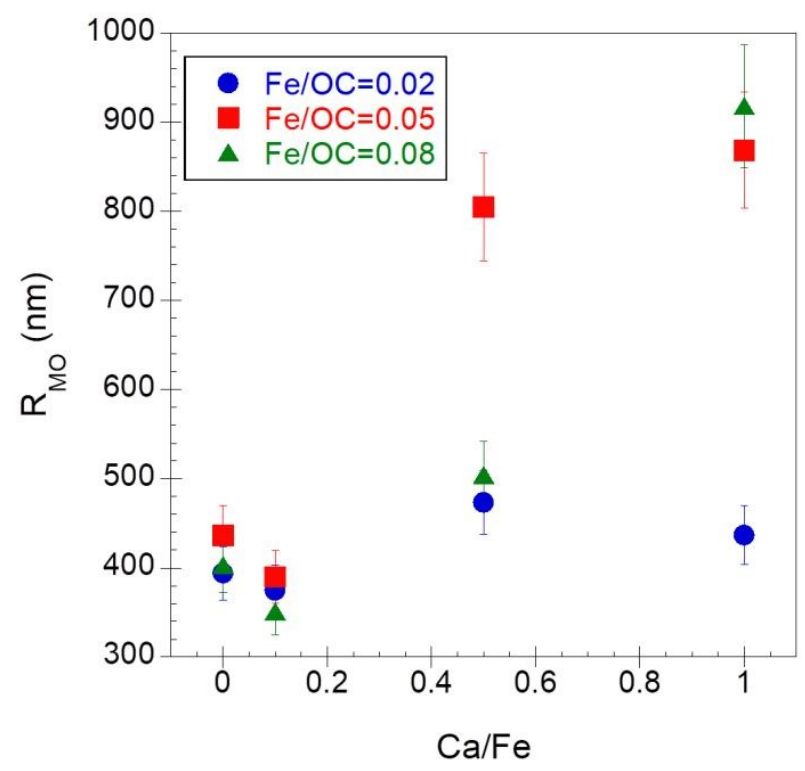

Figure 7 - Evolution of the $\mathrm{OM}$ radius relative to $\mathrm{Ca} / \mathrm{Fe}$ ratio.

\section{Calcium interaction with the aggregates}

Calcium interactions with the components of the Fe-OM aggregates were characterized by collecting XAS spectra at Ca K-edge. XANES spectra exhibit a pre-edge at $4041 \mathrm{eV}$ which is assigned to the $1 \mathrm{~s} \rightarrow 3 \mathrm{~d}$ transition ${ }^{61,62}$ with electric dipole character when the $3 \mathrm{~d}$ orbitals are 
hybridized with $\mathrm{p}$ orbitals and electric-quadrupole one (Figure 8). The $1 \mathrm{~s} \rightarrow 3 \mathrm{~d}$ electric dipipdedicle Online transition is forbidden for centrosymmetric complexes, then pre-edge structure gains only weak intensity from electric quadrupole transition. In calcite, $\mathrm{Ca}$ is surrounded by six $\mathrm{O}$ in an octahedral geometry ${ }^{63}$ so that the intensity of its pre-edge is relatively weak. The white line at $4045 \mathrm{eV}$ represents the $1 \mathrm{~s} \rightarrow 4 \mathrm{p}$ transition and the resonance at $4072 \mathrm{eV}$ corresponds to a $\mathrm{KL}_{\mathrm{II}, \mathrm{III}}$ multielectronic excitation ${ }^{62}$. Thus, according to Martin-Diaconescu et al. ${ }^{61}$, in our samples the lack of structure in the XANES spectra and the high intensity of the pre-edge indicate that more than six $\mathrm{O}$ are surrounding $\mathrm{Ca}$ in the first coordination shell.

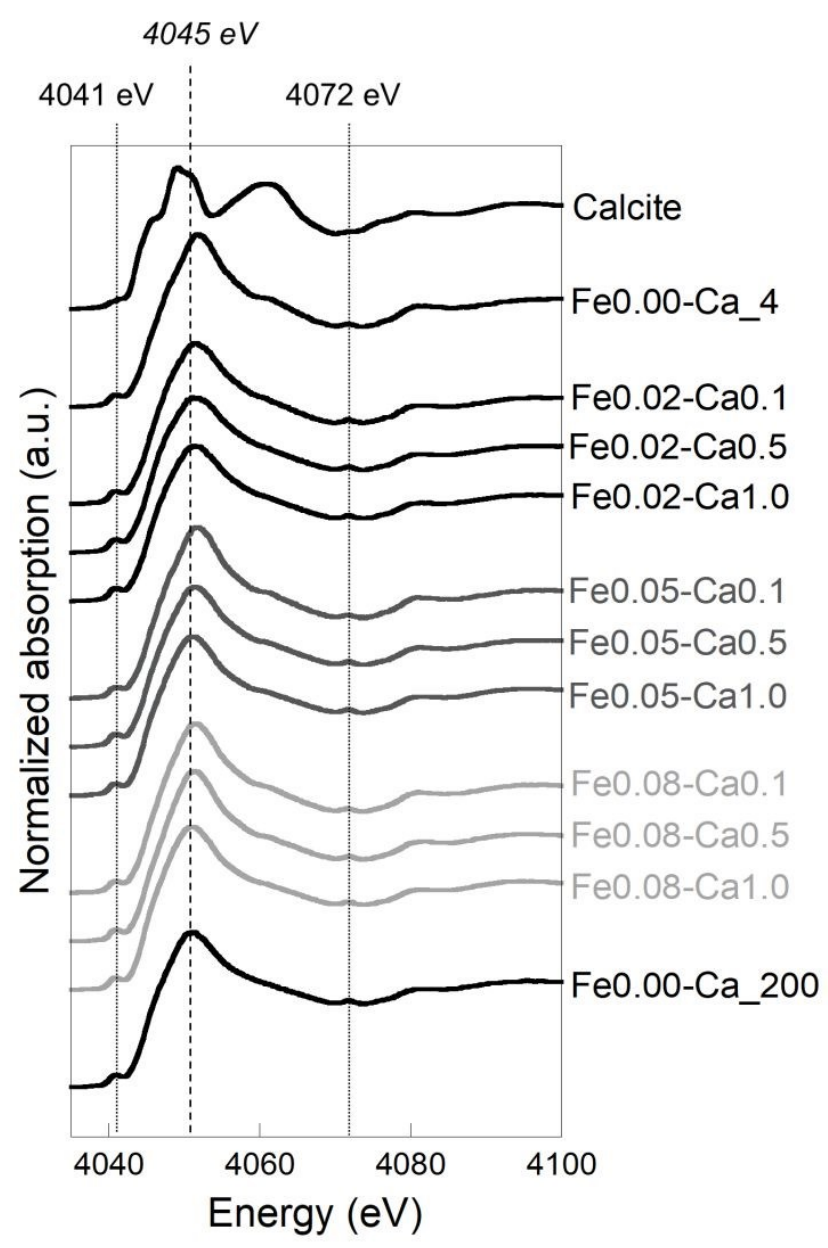

Figure 8 - Ca K-edge XANES spectra for sample.

Magnitude of EXAFS Fourier transform exhibits a first intense peak at $1.8 \AA \AA$ corresponding to the contribution of oxygens neighbours in the first coordination shell (Figure 9). A shoulder is visible for the highest Ca content at $2.1 \AA$. A second weak oscillation is observable at $2.8 \AA$ and 
a third more intense peak occurs at $3.3 \AA$, not corrected from phase shift. EXAFS spexptritricle Online (Figure SI 8) exhibit a maximum of amplitude at $4.5 \AA^{-1}$. A signal shift can be observed at the low $\mathrm{k}$ value for the highest Ca concentration. Two weak shoulders are also observed at 4 and 6 $\AA^{-1}$. Spectra were first fitted using two $\mathrm{Ca}-\mathrm{O}$ distances (Ca-O1 at $2.31 \AA$ and $\mathrm{Ca}-\mathrm{O} 2$ at $2.48 \AA$ ) for the first coordination shell of $\mathrm{Ca}$ that was used to reconstruct the first Fourier transform peak. The second peak was fitted with two different $\mathrm{C}$ as second neighbours $(\mathrm{Ca}-\mathrm{C} 1$ at $3.10 \AA$ and $\mathrm{Ca}-\mathrm{C} 2$ at $3.60 \AA$ ). A contribution of $\mathrm{Ca}$ as third nearest neighbours at $3.85 \AA$ was then used to fit the third peak, providing evidence of the formation of $\mathrm{Ca}$ dimers. The complete fit results are reported in Table 3. The detailed shell-by-shell fitting is reported in Figure SI 9. 
(a)

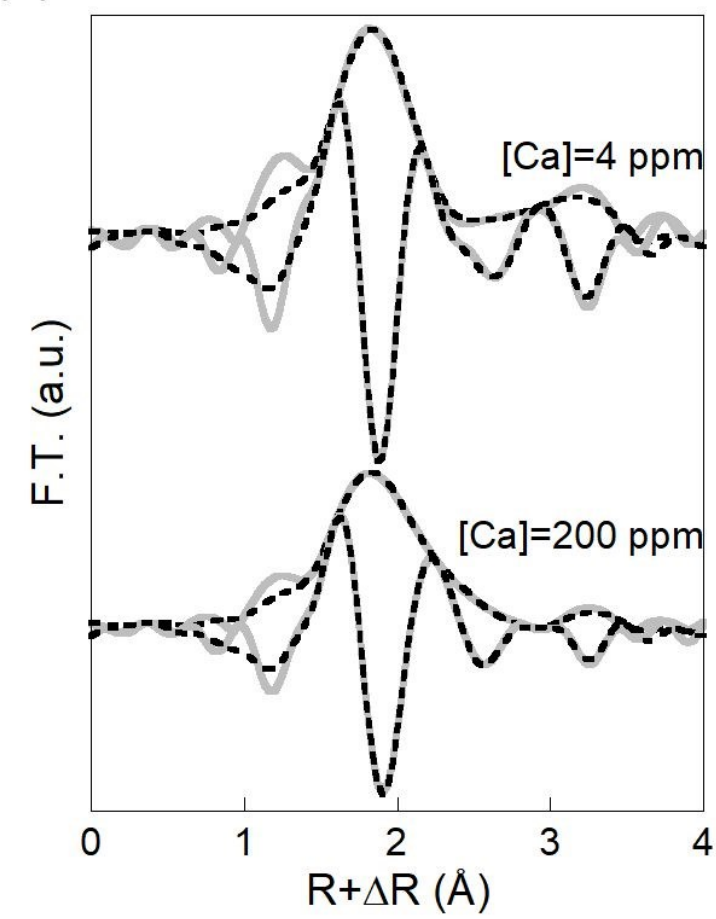

(c)

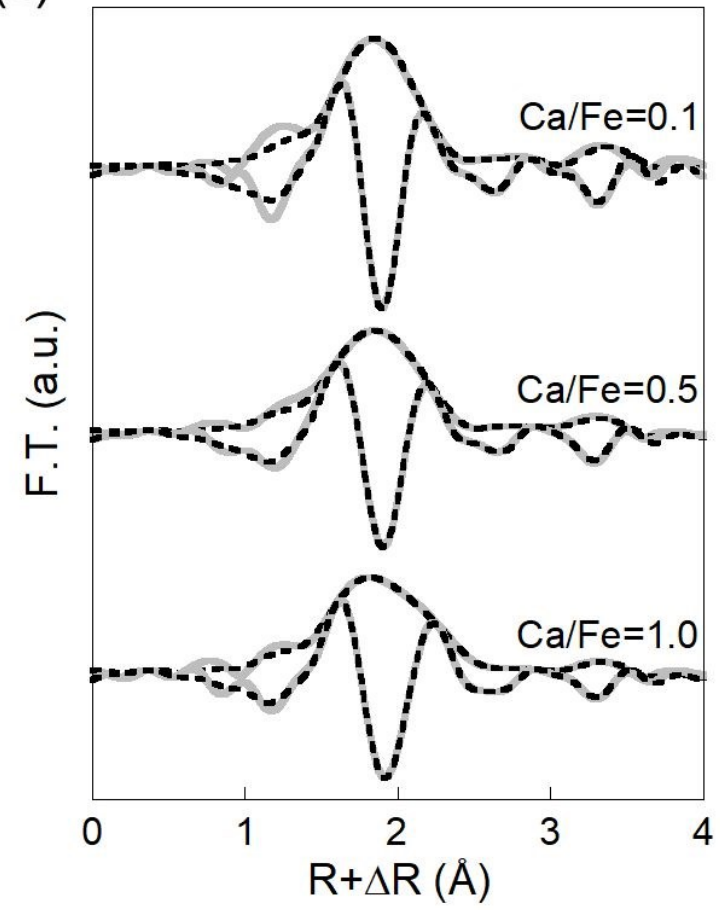

(b)

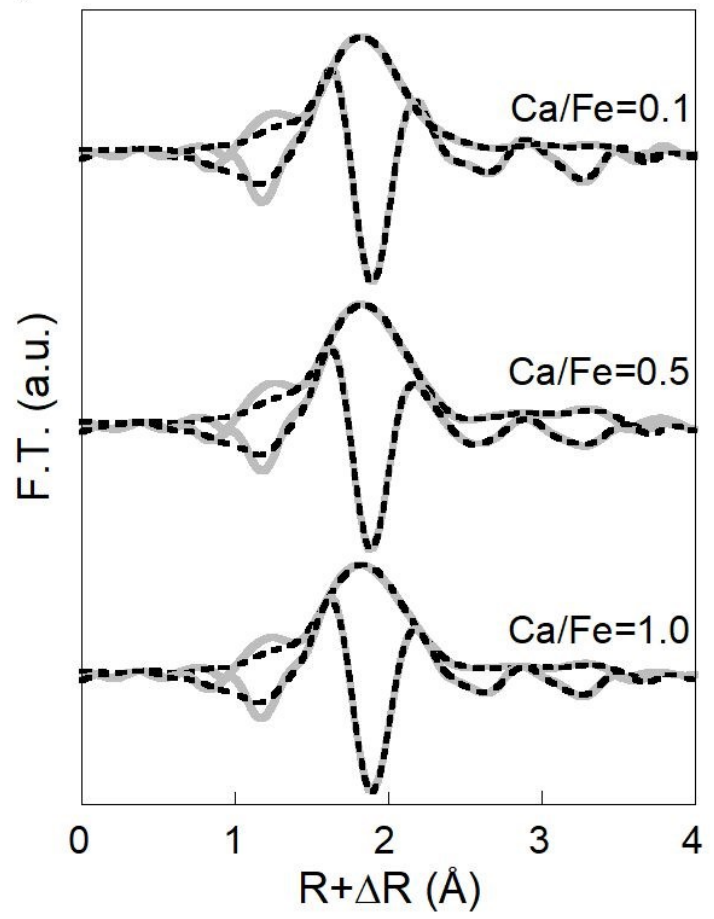

(d)

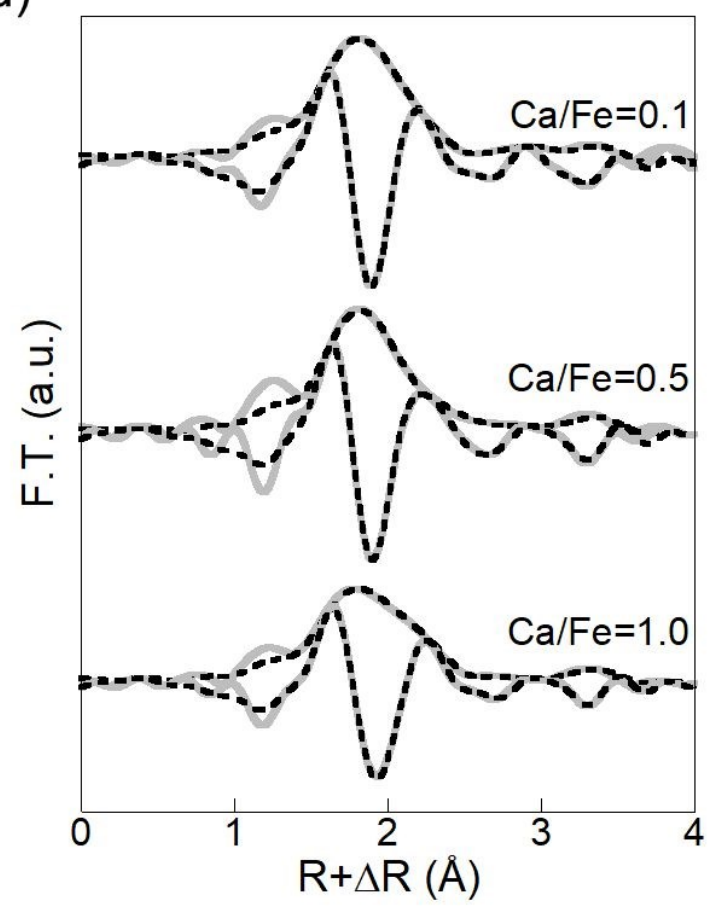

Figure 9 - Magnitude and imaginary part of the Fourier transform if the Ca K-edge EXAFS spectra for sample (a) without $\mathrm{Fe}$, (b) $\mathrm{Fe} / \mathrm{OC}=0.02$, (c) $\mathrm{Fe} / \mathrm{OC}=0.05$ and (d) $\mathrm{Fe} / \mathrm{OC}=0.08$. The grey solid lines are the experimental data and the black dotted lines are the fit results. 
Table 3 - Ca K-edge EXAFS fit results.

\begin{tabular}{|c|c|c|c|c|c|c|c|c|c|c|c|}
\hline \multirow{2}{*}{ Sample } & \multirow{2}{*}{ R-factor } & \multicolumn{2}{|c|}{ Ca-O1 } & \multicolumn{2}{|c|}{$\mathrm{Ca}-\mathrm{O} 2$} & \multicolumn{2}{|c|}{$\mathrm{Ca}-\mathrm{Cl}$} & \multicolumn{2}{|c|}{$\mathrm{Ca}-\mathrm{C} 2$} & \multicolumn{2}{|c|}{$\mathrm{Ca}-\mathrm{Ca}$} \\
\hline & & $N$ & $R(A)$ & $N$ & $R(A)$ & $N$ & $R(A)$ & $N$ & $R(A)$ & $N$ & $\boldsymbol{R}(A)$ \\
\hline $\mathrm{OM}-[\mathrm{Ca}]=4 \mathrm{ppm}$ & 0.0089 & 3.6 & 2.31 & 3.0 & 2.46 & 0.4 & 3.10 & 3.7 & 3.61 & 1.1 & 3.82 \\
\hline $\mathrm{Fe} 0.02-\mathrm{Ca} 0.1$ & 0.0033 & 3.4 & 2.31 & 3.2 & 2.47 & 0.5 & 3.09 & 2.7 & 3.59 & 0.9 & 3.83 \\
\hline $\mathrm{Fe} 0.02-\mathrm{Ca} 0.5$ & 0.0028 & 3.4 & 2.31 & 2.7 & 2.48 & 0.6 & 3.07 & 2.2 & 3.59 & 0.6 & 3.84 \\
\hline $\mathrm{Fe} 0.02-\mathrm{Ca} 1.0$ & 0.0029 & 3.1 & 2.31 & 2.8 & 2.47 & 0.6 & 3.09 & 2.0 & 3.58 & 0.6 & 3.82 \\
\hline $\mathrm{Fe} 0.05-\mathrm{Ca} 0.1$ & 0.0037 & 3.6 & 2.32 & 3.1 & 2.47 & 0.7 & 3.08 & 2.4 & 3.57 & 1.1 & 3.85 \\
\hline $\mathrm{Fe} 0.05-\mathrm{Ca} 0.5$ & 0.0035 & 2.9 & 2.30 & 3.3 & 2.46 & 0.6 & 3.09 & 2.0 & 3.61 & 0.8 & 3.84 \\
\hline $\mathrm{Fe} 0.05-\mathrm{Ca} 1.0$ & 0.0012 & 3.1 & 2.32 & 3.6 & 2.49 & 1.1 & 3.08 & 1.8 & 3.62 & 0.7 & 3.85 \\
\hline $\mathrm{Fe} 0.08-\mathrm{Ca} 0.1$ & 0.0024 & 3.6 & 2.31 & 3.3 & 2.48 & 0.6 & 3.10 & 2.6 & 3.60 & 0.8 & 3.85 \\
\hline $\mathrm{Fe} 0.08-\mathrm{Ca} 0.5$ & 0.0100 & 3.8 & 2.33 & 3.1 & 2.51 & 1.0 & 3.12 & 1.9 & 3.63 & 0.8 & 3.85 \\
\hline $\mathrm{Fe} 0.08-\mathrm{Ca} 1.0$ & 0.0038 & 3.0 & 2.33 & 3.2 & 2.51 & 0.7 & 3.14 & 1.3 & 3.66 & 0.6 & 3.86 \\
\hline $\mathrm{OM}-[\mathrm{Ca}]=200 \mathrm{ppm}$ & 0.0026 & 3.0 & 2.32 & 3.0 & 2.49 & 1.4 & 3.07 & 1.3 & 3.60 & 0.5 & 3.81 \\
\hline
\end{tabular}

The amplitude reduction factor $\mathrm{S}_{0}^{2}$ and theenergy shift parameter $\Delta \mathrm{E}$ were respectively set to 1.00 and $4.95 \mathrm{eV}$ by fitting the signal of calcite over the range of 1.3-4 $\AA$ (the calcite fit is reported in Figure SI 10 and the corresponding fitting parameters are reported in Table SI 4 ). $N$ is the coordination number and $R$ is the interatomic distance $(\AA)$. The Debye-Weller factors $\sigma^{2}$ were fixed to $0.004 \AA^{2}$ to compare the evolution of each coordination number. The error on $\mathrm{N}$ and $\mathrm{R}$ are usually estimated to be $\pm 10 \%$ and $\pm 1 \%$, respectively. 
The O number in the first coordination shell remains constant at $6.5 \pm 0.6$ for all the samüiplesticle Online This result is consistent with XANES data and is representative of a Ca coordination number higher than six for an organic $\mathrm{Ca}$ complex ${ }^{61}$ or hydrated soluble $\mathrm{Ca}^{62}$. In the second coordination shell, the $\mathrm{C}$ number also remains constant around $2.8 \pm 0.3$. Carbon in the second coordination shell is characteristic of the formation of $\mathrm{Ca}-\mathrm{OM}$ inner sphere complexes. The Ca number was also constant around $0.8 \pm 0.1$ demonstrating the formation of dimers. The $\mathrm{Ca}$-Ca distance at $3.85 \AA$ corresponds to Ca dimers bound by two O. To summarize, Ca forms dimers bound to $\mathrm{OM}$ as an inner sphere complex. Performing OC sorption experiments on Fh with $\mathrm{Ca}$, Sowers et al. ${ }^{64}$ suggested the formation of Fe-Ca-OC ternary complexes in which $\mathrm{Fe}$ was bound to $\mathrm{Ca}$ via an $\mathrm{O}$. The presence of the $\mathrm{Ca}-\mathrm{OC}$ inner complex occurrence is consistent with $\mathrm{Ca}$ binding to $\mathrm{OM}$ via carboxylic group as previously observed by Kalinichev and Kirkpatrick ${ }^{31}$ and Iskrenova-Tchoukova et al. ${ }^{65}$. In their studies, binding with phenolic groups was also suggested. However, for our experimental $\mathrm{pH}$ at 6.5 , phenolic groups remain protonated and weakly available for binding ${ }^{32}$. Moreover, during reduction, Adhikari et al. ${ }^{35}$ reported a higher release and degradation of phenolic OC as compared to carboxylic OC. Here, Ca binding to carboxylic groups is therefore the more expected process and no Fe neighbour could be added in the fit of the second coordination shell of the Ca EXAFS.

\section{Overall organization of Fe-OM-Ca aggregates}

The overall organization of Fe-OM-Ca associations was observed by cryo-TEM (Figure 10a,b and c) and cryo-TXM imaging (Figure 10d). The cryo-TEM observation of Fe0.08-Ca0.1 (Figure 10a) exhibits dispersed black spherical entities consistent with Fe-PA described from SAXS and observed by TEM (Figure 5). The yellow arrows highlight dots showing higher FePA density locally. They are embedded in a less intense background of $\square 100 \mathrm{~nm}$ which could be assigned to an OM aggregates. This aggregate was subjected to electron beam irradiation. During irradiation, some bubbles were formed (red arrows on Figure 10b) which indicates 
damaged organic compounds. Consequently, the $\square 100 \mathrm{~nm}$ aggregate highlighted by yell16xicle Online arrows was assigned to Fe-SA in an OM aggregate as described by Guénet et al. ${ }^{13}$. By contrast, for higher concentrations of $\mathrm{Ca}$, cryo-TEM observation of $\mathrm{Fe} 0.08-\mathrm{Ca} 0.5$ displays dispersed black dots embedded in a dark background (Figure 10c). These observations indicate Fe-PA embedded in an OM matrix and therefore correspond to an OM network trapping Fe-PA. The cryo-TXM observation of the same sample (Figure 10d) revealed darker features at the centre and on the right of the image, indicating the presence of $\mathrm{OM}, \mathrm{Ca}$ and $\mathrm{Fe}$ that confirms the micrometric network formation. These results clearly provide evidence for the significant impact of $\mathrm{Ca}$ on $\mathrm{Fe}-\mathrm{OM}$ structural organization, varying from aggregates to a micrometric network. 
(a)

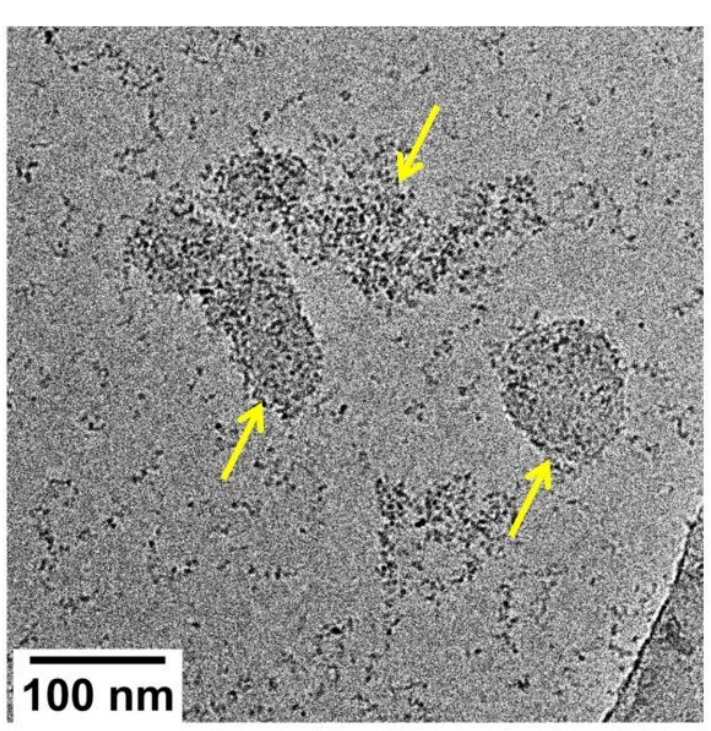

(c)

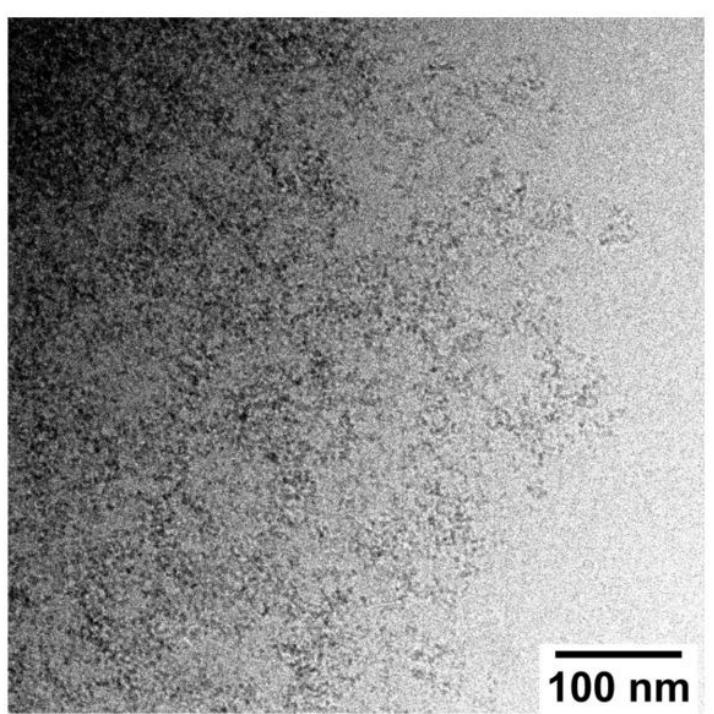

(b)

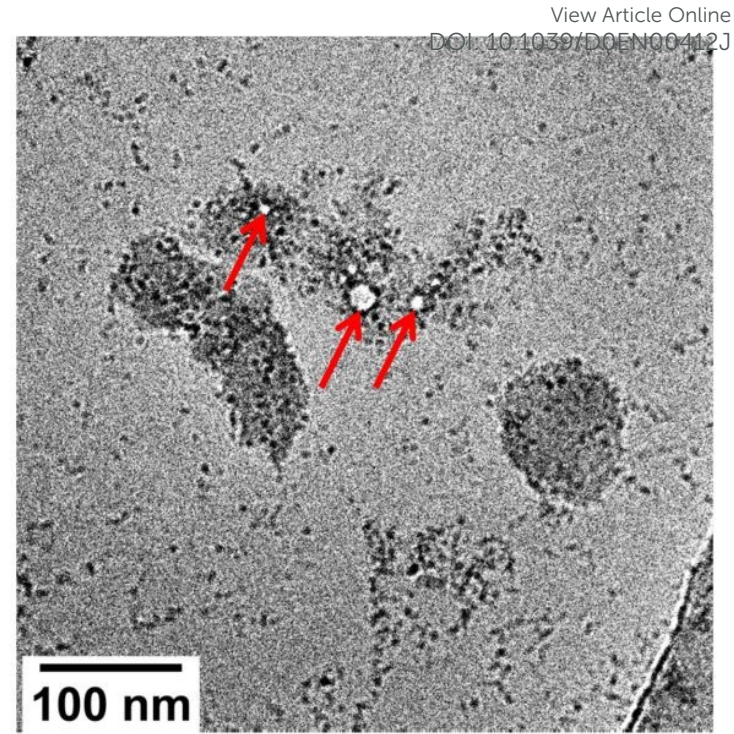

(d)

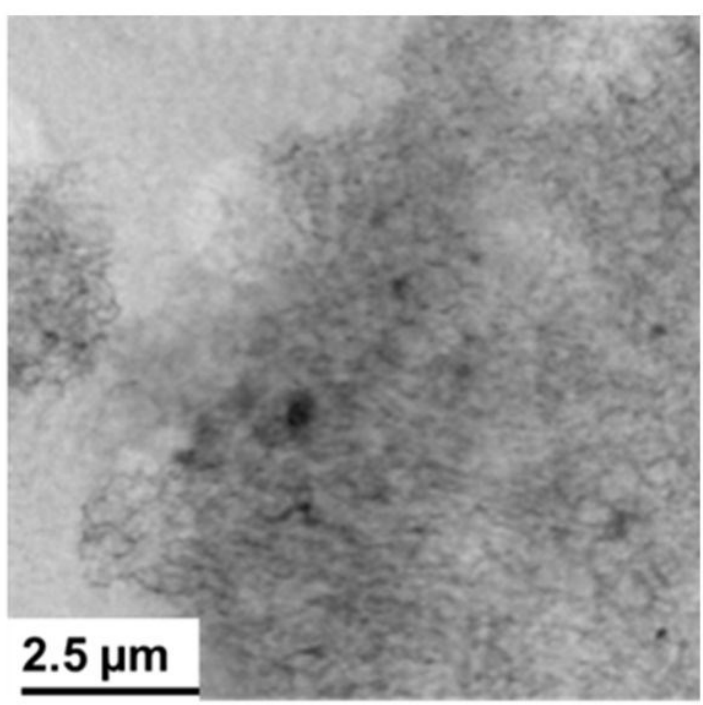

Figure 10 - Cryo-TEM imaging of (a) Fe0.08-Ca0.1, (b) Fe0.08-Ca0.1 after electron beam irradiation, (c) $\mathrm{Fe} 0.08-\mathrm{Ca} 0.5$ and (d) cryo-TXM imaging of $\mathrm{Fe} 0.08-\mathrm{Ca} 0.5$. The dense part at the bottom right in (a) and (b) corresponds to the thin carbon film on the grid. The $2 \mu \mathrm{m}$ white circles and a grey background in the top left of (d) correspond to the holes and the carbon film on of the grid, respectively.

The formation of a micrometric network was also confirmed with filtration and ultrafiltration experiments (Table 4). For Fe0.08-Ca0.1 the presence of OM, Fe and $\mathrm{Ca}$ in the $>0.2 \mu \mathrm{m}$ and $0.2 \mu \mathrm{m}-30 \mathrm{kDa}$ fractions demonstrated the existence of aggregates with a size $<200 \mathrm{~nm}$. For $\mathrm{Fe} 0.08-\mathrm{Ca} 0.5,96 \%$ of the $\mathrm{OC}$ and $100 \%$ of the $\mathrm{Fe}$ is in the $>0.2 \mu \mathrm{m}$ fraction while SAXS measurements and TEM observations provided evidence of the existence of Fe-PA with a size $\approx 5 \mathrm{~nm}$. These results encouraged the formation of an OM micrometric network trapping Fe-

PA. 
Table 4 - OC, $\mathrm{Ca}$ and $\mathrm{Fe}$ concentration $\left(\mathrm{mmol} \mathrm{L}^{-1}\right)$ for $\mathrm{Fe} 0.08-\mathrm{Ca} 0.1$ and $\mathrm{Fe} 0.08-\mathrm{Ca} 0.5$. $<\mathrm{LOD}$ : below the Yimmitticle Online of detection (LOD).

\begin{tabular}{llllllll}
\hline \multirow{2}{*}{ Fractions } & \multicolumn{2}{l}{ Fe0.08-Ca0.1 } & & \multicolumn{2}{l}{ Fe0.08-Ca0.5 } & \\
\cline { 2 - 3 } & OC & Ca & Fe & OC & Ca & Fe \\
\hline$>0.2 \mu \mathrm{m}$ & $36.5 \pm 3.2$ & $0.35 \pm 0.02$ & $3.4 \pm 0.3$ & $54.9 \pm 2.1$ & $1.2 \pm 0.1$ & $4.77 \pm 0.1$ \\
$0.2 \mu \mathrm{m}-30 \mathrm{kDa}$ & $17.4 \pm 3.2$ & $0.17 \pm 0.03$ & $1.6 \pm 0.3$ & $<$ LOD & $<$ LOD & $<$ LOD \\
$<30 \mathrm{kDa}$ & $2.3 \pm 0.3$ & $0.05 \pm 0.01$ & $<$ LOD & $2.2 \pm 0.4$ & $1.2 \pm 0.1$ & $<$ LOD \\
\hline
\end{tabular}

\section{Fe-OM-Ca associations: from aggregates to a micrometric network}

It was demonstrated that calcium controls the structural organization of the Fe-OM-Ca association through its binding to $\mathrm{OM}$ via carboxylic groups $(\mathrm{COOH})$. It is thus appropriate to present the results depending on $\mathrm{Ca} / \mathrm{OC}$ molar ratio since SANS measurements highlight a significant increase of the $\mathrm{OM}$ size from $\mathrm{Ca} / \mathrm{OC} \geq 0.026$ (Figure 11). This observation is in accordance with cryo-TEM and cryo-TXM images which provide evidence of the OM micrometric network formation from $\mathrm{Ca} / \mathrm{OC} \geq 0.026$.

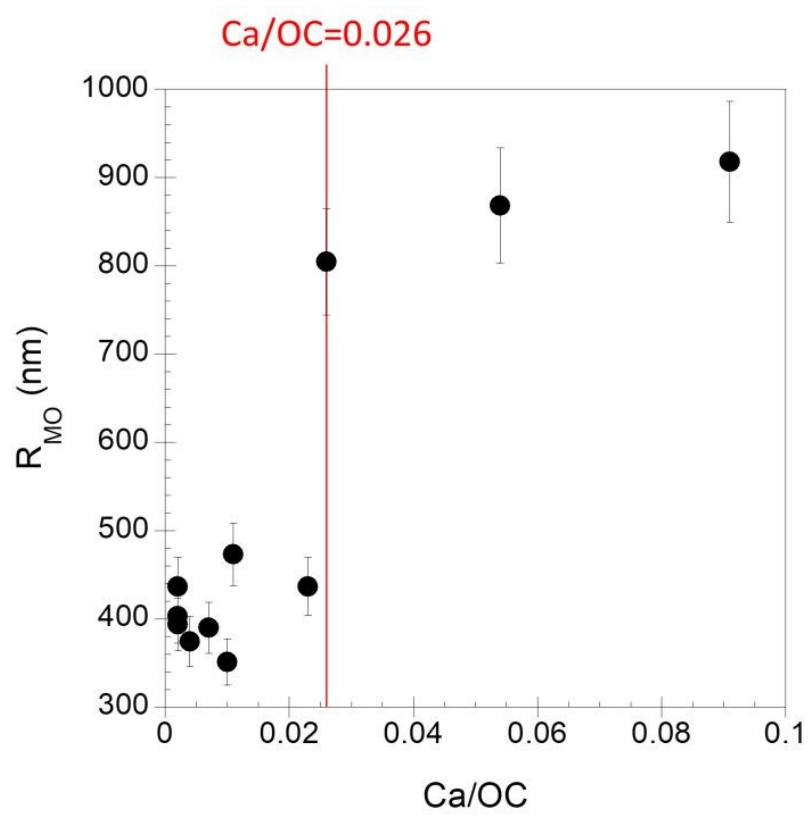

Figure 11 - Evolution of the $\mathrm{OM}$ radius relative to $\mathrm{Ca} / \mathrm{OC}$ ratio.

Fe-OM-Ca associations therefore exhibit two distinct organizations depending on the $\mathrm{Ca} / \mathrm{OC}$ ratio. For $\mathrm{Ca} / \mathrm{OC}<0.026, \mathrm{Fe}-\mathrm{OM}-\mathrm{Ca}$ associations are organized as aggregates. Iron exhibits a fractal organization in which Fe-PB (radius $\approx 0.8 \mathrm{~nm}$ ) formed Fe-PA (radius $\approx 5 \mathrm{~nm}$ ) that is 
either isolated or embedded in an OM aggregate (radius $\square 100 \mathrm{~nm}$ ) resulting in the formbitionticle Online of Fe-SA (radius $>100 \mathrm{~nm}$ ), as already described ${ }^{13}$ (Figure 12, left). For $\mathrm{Ca} / \mathrm{OC} \geq 0.026$, the organization of the Fe-OM-Ca association is drastically different. All OM is branched out by $\mathrm{Ca}$ and forms a micrometric network in which all Fe-PB and Fe-PA are embedded (Figure 12, right). The presence of $\mathrm{Ca}$ also results in an increase in Fe-PA size from $2 \mathrm{~nm}$ to $5 \mathrm{~nm}$. Therefore, while $\mathrm{Ca}$ did not directly interact with $\mathrm{Fe}, \mathrm{Ca}$ atoms screen interactions between $\mathrm{Fe}$ and OM thereby allowing for the growth of Fe-PA. Calcium drives the organizational mechanism of $\mathrm{OM}$ which in turn controls the size and the distribution of Fe-PA in the OM aggregate or in the OM network. Thus, calcium drives the structural transition in this system. These significant modifications of the structural organizations modify the size of the global aggregates and their colloidal stability (Figure SI 1). For $\mathrm{Ca} / \mathrm{OC}<0.026$, Fe-OM-Ca associations are composed of aggregates which stay in suspension and can be transported with the water flow. For $\mathrm{Ca} / \mathrm{OC} \geq 0.026$, the formation of a micrometric network results in the settlement of Fe-OM-Ca associations and their immobilization by gravitational settling and/or trapping the soil porous media ${ }^{66}$. 


\section{Fe-OM-Ca aggregates}

Fe seccondary aggregate embedded

in an OM aggregate
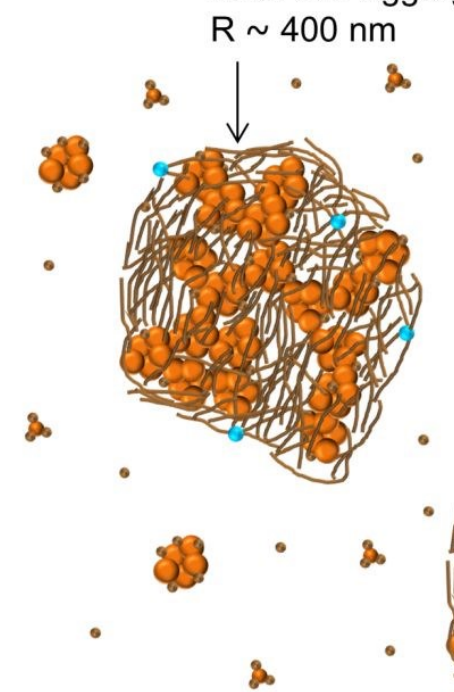

Fe primary aggregate: Ferrihydrite-like nanoparticles

$$
\mathrm{R} \sim 2 \mathrm{~nm}
$$

\section{Fe-OM-Ca micrometric network}

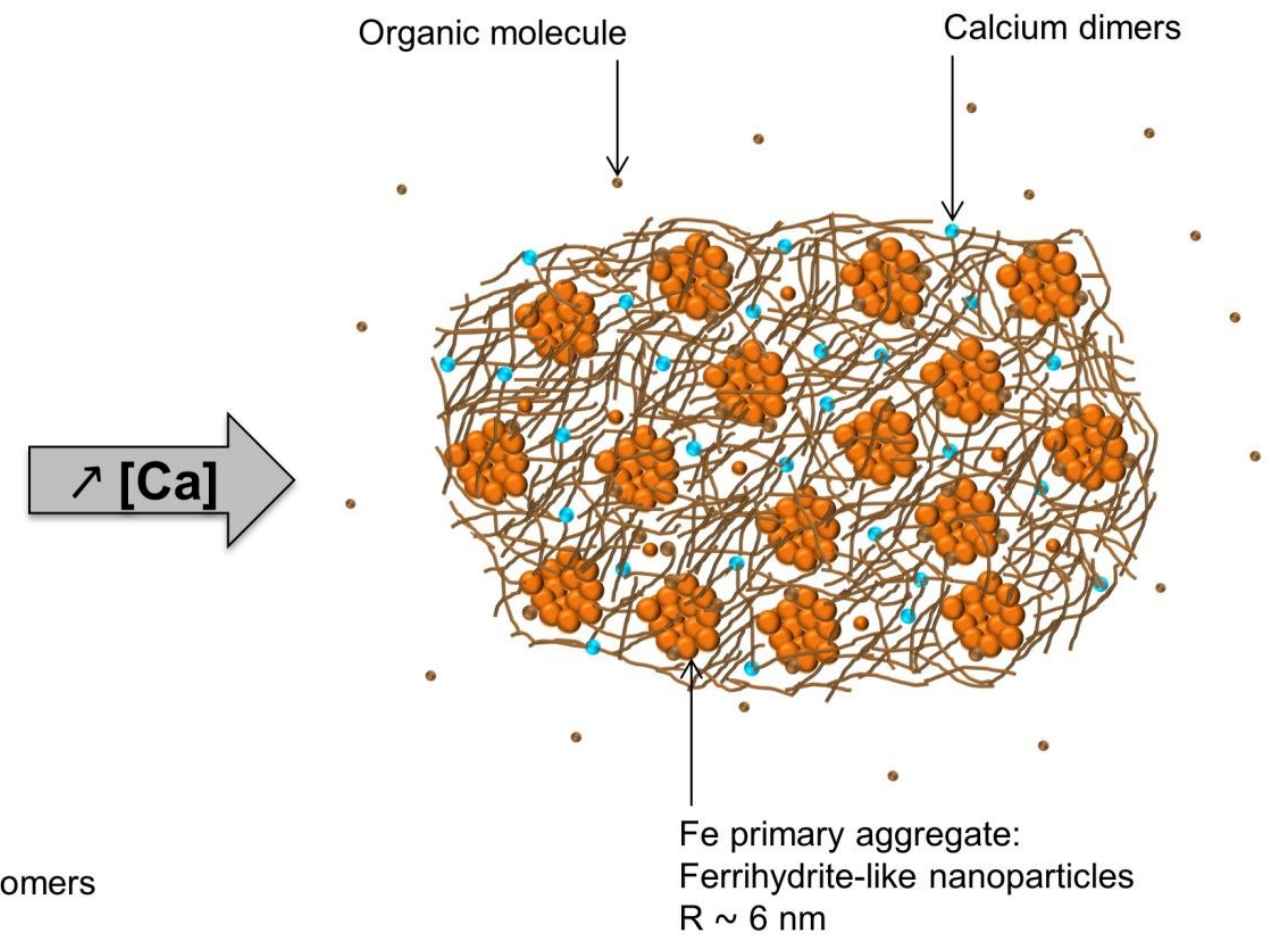

$\mathrm{Ca} / \mathrm{OC} \geq 0.026$

Figure 12 - Schematic representation of the structural organization of the Fe-OM-Ca associations depending on the $\mathrm{Ca} / \mathrm{OC}$ ratio. 
In environmental waters, $\mathrm{OM}$ is known to control Fe phases by inhibiting their grownthy hiowndidcle Online crystallinity. Organic matter also enables the formation of complexes formed with a $\mathrm{Fe}$ oligomer and its carboxylic functional group ${ }^{13-15,17}$. Given that Leonardite HA is composed of $7.46 \times 10^{-3} \mathrm{~mol}$ of $\mathrm{COOH}$ per gram of $\mathrm{C}^{67}$, an apparent $\mathrm{COOH}$ concentration can be calculated for our samples (Table 5). In Fe-OM-Ca associations, $\mathrm{Ca}$ is bound to $\mathrm{OM}$ via $\mathrm{COOH}$ with a $\mathrm{COOH} / \mathrm{Ca}=3$. For $\mathrm{Fe} 0.08-\mathrm{Ca} 0.1$, the $\mathrm{COOH} / \mathrm{Ca}$ ratio within aggregates is close to 9 and therefore some carboxylic groups remain available for the Fe phases. For Fe0.08-Ca0.5, $\mathrm{COOH} / \mathrm{Ca}=4.2$ in the $\mathrm{OM}$ micrometric network. As a consequence, carboxylic groups are less available for binding the Fe species. In the OM network, Fe phases are not as covered by the organic molecule and their adsorption capacity should therefore be higher. Furthermore, for the highest $\mathrm{Ca}$ amounts, the $\mathrm{Fe}(\mathrm{III})$-oligomer content decreases in favour of $\mathrm{Fh}$, increasing the sorption capacities of the Fe aggregates. Conversely, the size of the nanoparticular Fe phases is allowed to increase and nanoparticles larger than $20 \mathrm{~nm}$ exhibit lower adsorption capacities ${ }^{68}$. The Fe-OM-Ca adsorption capacities could therefore be lower with increasing $\mathrm{Ca}$ amounts and the subsequent continuous network formation. The formation of a continuous network leads to two antagonist effects with regard to the Fe-OM-Ca adsorption capacities, which need to be investigated in further studies. In addition, the presence of $\mathrm{Ca}$ should impact the Fe-OM aggregates reactivity regards bioreduction processes. Pédrot et al. ${ }^{17}$ demonstrated that the bioreduction of $\mathrm{Fe}(\mathrm{III})-\mathrm{OM}$ colloids was significantly faster than that of nano-Lp. They suggested that $\mathrm{OM}$ acts as an electron shuttle during the reduction process. Adhikari et al. ${ }^{35}$ reported a decrease of the Fh-OM co-precipitates bioreduction rate in the presence of Ca. The partial screening of the interactions between Fe and OM evidenced in our study could explain this result: the $\mathrm{OM}$, bound to $\mathrm{Ca}$, could not act as electron shuttle anymore. 
Table 5 - Concentration of the carboxylic groups $(\mathrm{COOH})\left(\mathrm{mol} \mathrm{L}^{-1}\right)$ and $\mathrm{COOH} / \mathrm{Ca}$ ratios for Fe0.08-Ca0. Yieandelticle Online $\mathrm{Fe} 0.08-\mathrm{Ca} 0.5$.

\begin{tabular}{|c|c|c|c|c|}
\hline \multirow{2}{*}{ Fractions } & \multirow{2}{*}{$\frac{\text { Fe0.08-Ca0.1 }}{\text { COOH }\left(\mathrm{mol} \mathrm{L}^{-1}\right)}$} & \multirow[b]{2}{*}{$\mathrm{COOH} / \mathrm{Ca}$} & \multirow{2}{*}{$\begin{array}{l}\mathrm{Fe} 0.08-\mathrm{Ca0.5} \\
\mathrm{COOH}\left(\mathrm{mol} \mathrm{L}^{-1}\right)\end{array}$} & \multirow[b]{2}{*}{$\mathrm{COOH} / \mathrm{Ca}$} \\
\hline & & & & \\
\hline$>0.2 \mu \mathrm{m}$ & $3.22 \times 10^{-3}$ & 9.2 & $4.92 \times 10^{-3}$ & 4.2 \\
\hline $0.2 \mu \mathrm{m}-30 \mathrm{kDa}$ & $1.56 \times 10^{-3}$ & 8.7 & - & - \\
\hline
\end{tabular}

\section{Conclusion}

We demonstrated the impact of $\mathrm{Ca}$ on the structural organization of $\mathrm{Fe}-\mathrm{OM}$ aggregates. The structural organization of Fe-OM-Ca associations is controlled by the occurrence of Ca through its binding to $\mathrm{OM}$ carboxylic groups. Fe-OM-Ca associations can have two distinct organizations depending on the $\mathrm{Ca} / \mathrm{OC}$ ratio. For low $\mathrm{Ca}$ concentrations, $\mathrm{Fe}-\mathrm{OM}-\mathrm{Ca}$ associations are organized as aggregates in which Fe exhibits three aggregation levels: (i) isolated Fe primary beads bound to organic molecules, that can be aggregated as (ii) Fe primary aggregates which can themselves form (iii) Fe secondary aggregates embedded in an OM aggregate (Figure 12). A structural transition occurs with the increasing $\mathrm{Ca} / \mathrm{OC}$ ratio until an OM micrometric network is formed. This structural transition is driven by $\mathrm{Ca}$ which mainly interacts with $\mathrm{OM} \mathrm{COOH}$ sites. Calcium acts as a bridge between the organic molecules and allows the formation of a large OM network. As organic molecules are preferentially connected to each other by $\mathrm{Ca}$ bridges, they are less available for binding Fe which is less covered by OM, allowing for the growth of ferrihydrite-like nanoparticular structures as indicated by their size increase. The impact of $\mathrm{Ca}$ on the overall structural organization is of major importance regarding the increase of $\mathrm{Ca}$ amounts in surface waters due to the permafrost thawing, which one is enhanced by climate change ${ }^{69}$. Moreover, the interaction of $\mathrm{Ca}$ with $\mathrm{OM}$ increases the Fh-like binding sites availability and prevents the ability of OM to act as an electron shuttle in bioreduction processes. Finally, the Ca occurrence controls the mobility of Fe-OM aggregates and associated elements through the formation of a micrometric network. 


\section{Acknowledgments}

This study is part of a Ph.D. funded by the French administrative region Brittany and by the SOLEIL-LLB through the 'ORPHREA' project and the French "Institut national des sciences de l'Univers" (INSU) through the "Initiative Structurante EC2CO - BIOHEFECT" allocated to Dr. Delphine Vantelon via the 'ISAAP' project. The authors are grateful to Dr. Gildas Ratié for his help in presenting the figures. Ludivine Rault is acknowledged for the TEM observations. The authors acknowledge SOLEIL for beamtime allocation at the LUCIA beamline (proposal 99170211) and ROCK beamline (proposal 20170795). The work at ROCK was supported by a public grant overseen by the French National Research Agency (ANR) as a part of the "Investissements d'Avenir" program ref: ANR-10-EQPX-45. These experiments were performed at MISTRAL beamline at ALBA Synchrotron with the collaboration of ALBA staff. This work is based upon experiments performed at the KWS-2 and KWS-3 instruments operated by JCNS at the Heinz Maier-Leibnitz Zentrum (MLZ), Garching, Germany. The authors gratefully acknowledge the financial support provided by JCNS to perform the neutron scattering measurements at the Heinz Maier-Leibnitz Zentrum (MLZ), Garching, Germany. This work benefited from the use of the SasView application, originally developed under NSF award DMR-0520547. SasView contains code developed with funding from the European Union's Horizon 2020 research and innovation programme under the SINE2020 project, grant agreement No 654000. Dr Sara Mullin is acknowledged for post-editing the English style. 
1 N. S. Wigginton, K. L. Haus and M. F. Hochella Jr, Aquatic environmental nanoparticles, J. Environ. Monit., 2007, 9, 1306.

2 H. Guénet, M. Davranche, D. Vantelon, M. Pédrot, M. Al-Sid-Cheikh, A. Dia and J. Jestin, Evidence of organic matter control on As oxidation by iron oxides in riparian wetlands, Chem. Geol., 2016, 439, 161-172.

3 E. Lotfi-Kalahroodi, A.-C. Pierson-Wickman, H. Guenet, O. Rouxel, E. Ponzevera, M. Bouhnik-Le Coz, D. Vantelon, A. Dia and M. Davranche, Iron isotope fractionation in ironorganic matter associations: Experimental evidence using filtration and ultrafiltration, Geochim. Cosmochim. Acta, 2019, 250, 98-116.

4 G. Ratié, D. Vantelon, E. Lotfi Kalahroodi, I. Bihannic, A. C. Pierson-Wickmann and M. Davranche, Iron speciation at the riverbank surface in wetland and potential impact on the mobility of trace metals, Sci. Total Environ., 2019, 651, 443-455.

5 O. S. Pokrovsky, B. Dupré and J. Schott, Fe-Al-organic Colloids Control of Trace Elements in Peat Soil Solutions: Results of Ultrafiltration and Dialysis, Aquat. Geochem., 2005, 11, 241-278.

6 L. K. ThomasArrigo, C. Mikutta, J. Byrne, K. Barmettler, A. Kappler and R. Kretzschmar, Iron and Arsenic Speciation and Distribution in Organic Flocs from Streambeds of an Arsenic-Enriched Peatland, Environ. Sci. Technol., 2014, 48, 13218-13228.

7 O. S. Pokrovsky and J. Schott, Iron colloids/organic matter associated transport of major and trace elements in small boreal rivers and their estuaries (NW Russia), Chem. Geol., 2002, 190, 141-179.

8 C. Hirst, P. S. Andersson, S. Shaw, I. T. Burke, L. Kutscher, M. J. Murphy, T. Maximov, O. S. Pokrovsky, C.-M. Mörth and D. Porcelli, Characterisation of Fe-bearing particles and colloids in the Lena River basin, NE Russia, Geochim. Cosmochim. Acta, 2017, 213, 553573.

9 B. Stolpe, L. Guo, A. M. Shiller and G. R. Aiken, Abundance, size distributions and traceelement binding of organic and iron-rich nanocolloids in Alaskan rivers, as revealed by fieldflow fractionation and ICP-MS, Geochim. Cosmochim. Acta, 2013, 105, 221-239.

10M. Pédrot, A. Dia, M. Davranche, M. Bouhnik-Le Coz, O. Henin and G. Gruau, Insights into colloid-mediated trace element release at the soil/water interface, J. Colloid Interface Sci., 2008, 325, 187-197.

11C. Mikutta and R. Kretzschmar, Spectroscopic Evidence for Ternary Complex Formation between Arsenate and Ferric Iron Complexes of Humic Substances, Environ. Sci. Technol., 2011, 45, 9550-9557.

12 K. Ritter, G. Aiken R., J. F. Ranville, M. Bauer and D. L. Macalady, Evidence for the Aquatic Binding of Arsenate by Natural Organic Matter-Suspended Fe(III), Environ. Sci. Technol., 2006, 40, 5380-5387.

13 H. Guénet, M. Davranche, D. Vantelon, J. Gigault, S. Prévost, O. Taché, S. Jaksch, M. Pédrot, V. Dorcet, A. Boutier and J. Jestin, Characterization of iron-organic matter nanoaggregate networks through a combination of SAXS/SANS and XAS analyses: impact on As binding, Environ. Sci. Nano, 2017, 4, 938-954.

14D. Vantelon, M. Davranche, R. Marsac, C. La Fontaine, H. Guénet, J. Jestin, G. Campaore, A. Beauvois and V. Briois, Iron speciation in iron-organic matter nanoaggregates: A kinetic approach coupling Quick-EXAFS and MCR-ALS chemometry, Environ. Sci. Nano, 2019, 6, 2641-2651.

15 T. Karlsson and P. Persson, Coordination chemistry and hydrolysis of Fe(III) in a peat humic acid studied by X-ray absorption spectroscopy, Geochim. Cosmochim. Acta, 2010, 74, 3040 . 
16C. Mikutta, X-ray absorption spectroscopy study on the effect of hydroxybenzoic acidsw onticle Online the formation and structure of ferrihydrite, Geochim. Cosmochim. Acta, 2011, 75, 51225139.

17 M. Pédrot, A. L. Boudec, M. Davranche, A. Dia and O. Henin, How does organic matter constrain the nature, size and availability of Fe nanoparticles for biological reduction?, $J$. Colloid Interface Sci., 2011, 359, 75-85.

18 C. Chen, J. J. Dynes, J. Wang and D. L. Sparks, Properties of Fe-Organic Matter Associations via Coprecipitation versus Adsorption, Environ. Sci. Technol., 2014, 48, 13751-13759.

19T. Karlsson and P. Persson, Complexes with aquatic organic matter suppress hydrolysis and precipitation of Fe(III), Chem. Geol., 2012, 322-323, 19-27.

20 L. K. ThomasArrigo, J. M. Byrne, A. Kappler and R. Kretzschmar, Impact of Organic Matter on Iron(II)-Catalyzed Mineral Transformations in Ferrihydrite-Organic Matter Coprecipitates, Environ. Sci. Technol., 2018, 52, 12316-12326.

21C. Mikutta, R. Mikutta, S. Bonneville, F. Wagner, A. Voegelin, I. Christl and R. Kretzschmar, Synthetic coprecipitates of exopolysaccharides and ferrihydrite. Part I: Characterization, Geochim. Cosmochim. Acta, 2008, 72, 1111-1127.

22 T. Karlsson, P. Persson, U. Skyllberg, C.-M. Mörth and R. Giesler, Characterization of Iron(III) in Organic Soils Using Extended X-ray Absorption Fine Structure Spectroscopy, Environ. Sci. Technol., 2008, 42, 5449-5454.

23 S. D. Herzog, L. Gentile, U. Olsson, P. Persson and E. S. Kritzberg, Characterization of Iron and Organic Carbon Colloids in Boreal Rivers and Their Fate at High Salinity, J. Geophys. Res. Biogeosciences, 2020, 125, 1-14.

24 U. Schwertmann and R. M. Cornell, Eds., Iron Oxides in the Laboratary, Wiley-VCH Verlag GmbH, Weinheim, Germany, 2000.

25 J. W. J. van Schaik, I. Persson, D. B. Kleja and J. P. Gustafsson, EXAFS Study on the Reactions between Iron and Fulvic Acid in Acid Aqueous Solutions, Environ. Sci. Technol., 2008, 42, 2367-2373.

26 M. Baalousha, A. Manciulea, S. Cumberland, K. Kendall and J. R. Lead, Aggregation and surface properties or iron oxide nanoparticles: influence of $\mathrm{pH}$ and natural organic matter, Environ. Toxicol. Chem., 2008, 27, 1875.

27 M. J. Pullin and S. E. Cabaniss, The effects of $\mathrm{pH}$, ionic strength, and iron-fulvic acid interactions on the kinetics of non-photochemical iron transformations. I. Iron(II) oxidation and iron(III) colloid formation, Geochim. Cosmochim. Acta, 2003, 67, 4067-4077.

28 A. Iglesias, R. López, S. Fiol, J. M. Antelo and F. Arce, Analysis of copper and calciumfulvic acid complexation and competition effects, Water Res., 2003, 37, 3749-3755.

29 A. Ouatmane, M. Hafidi, M. EL Gharous and J. C. Revel, Complexation of calcium ions by humic and fulvic acids, Analusis, 1999, 27, 428-431.

30I. Christl, Ionic strength- and $\mathrm{pH}$-dependence of calcium binding by terrestrial humic acids, Environ. Chem., 2012, 9, 89.

31 A. G. Kalinichev and R. J. Kirkpatrick, Molecular dynamics simulation of cationic complexation with natural organic matter, Eur. J. Soil Sci., 2007, 58, 909-917.

32 J. Adusei-Gyamfi, B. Ouddane, L. Rietveld, J.-P. Cornard and J. Criquet, Natural organic matter-cations complexation and its impact on water treatment: A critical review, Water Res., 2019, 160, 130-147.

33 L. P. Weng, L. K. Koopal, T. Hiemstra, J. C. L. Meeussen and W. H. Van Riemsdijk, Interactions of calcium and fulvic acid at the goethite-water interface, Geochim. Cosmochim. Acta, 2005, 69, 325-339.

$34 \mathrm{~N}$. Kloster and M. Avena, Interaction of humic acids with soil minerals: adsorption and surface aggregation induced by Ca2+, Environ. Chem., 2015, 12, 731. 
35D. Adhikari, T. Sowers, J. W. Stuckey, X. Wang, D. L. Sparks and Y. Yang, Formation redox reactivity of ferrihydrite-organic carbon-calcium co-precipitates, Geochim. Cosmochim. Acta, 2019, 244, 86-98.

36C. C. Davis and M. Edwards, Role of Calcium in the Coagulation of NOM with Ferric Chloride, Environ. Sci. Technol., 2017, 51, 11652-11659.

37 A.-M. Flank, G. Cauchon, P. Lagarde, S. Bac, M. Janousch, R. Wetter, J.-M. Dubuisson, M. Idir, F. Langlois, T. Moreno and D. Vantelon, LUCIA, a microfocus soft XAS beamline, Nucl. Instrum. Methods Phys. Res. Sect. B Beam Interact. Mater. At., 2006, 246, 269-274.

38D. Vantelon, N. Trcera, D. Roy, T. Moreno, D. Mailly, S. Guilet, E. Metchalkov, F. Delmotte, B. Lassalle, P. Lagarde and A.-M. Flank, The LUCIA beamline at SOLEIL, J. Synchrotron Radiat., 2016, 23, 635-640.

39V. Briois, C. La Fontaine, S. Belin, L. Barthe, T. Moreno, V. Pinty, A. Carcy, R. Girardot and E. Fonda, ROCK: the new Quick-EXAFS beamline at SOLEIL, J. Phys. Conf. Ser., 2016, 712, 012149.

40B. Ravel and M. Newville, ATHENA , ARTEMIS , HEPHAESTUS : data analysis for X-ray absorption spectroscopy using IFEFFIT, J. Synchrotron Radiat., 2005, 12, 537-541.

41 E. A. Klop, A. Schouten, P. van der Sluis and A. L. Spek, Structure of calcium acetate monohydrate, $\mathrm{Ca}(\mathrm{C} 2 \mathrm{H} 3 \mathrm{O} 2) 2 . \mathrm{H} 2 \mathrm{O}$, Acta Crystallogr. C, 1984, 40, 51-53.

42B. Paluchowska, J. K. Maurin and J. Leciejewicz, Carboxylate and Furan-Ring Oxygen Bonded to Calcium in Polymeric Calcium Furoate, Acta Crystallogr. C, 1996, 52, 347-351.

43 M. Newville, EXAFS analysis using FEFF and FEFFIT, J. Synchrotron Radiat., 2001, 8, 96-100.

44 J. J. Rehr, R. C. Albers and S. I. Zabinsky, High-order multiple-scattering calculations of xray-absorption fine structure, Phys. Rev. Lett., 1992, 69, 3397-3400.

45 A. Radulescu, N. K. Szekely and M.-S. Appavou, KWS-2: Small angle scattering diffractometer, J. Large-Scale Res. Facil. JLSRF, 2015, 1, A29.

46V. Pipich and Z. Fu, KWS-3: Very small angle scattering diffractometer with focusing mirror, J. Large-Scale Res. Facil. JLSRF, 2015, 1, A31.

47B. Hammouda, A new Guinier-Porod model, J. Appl. Crystallogr., 2010, 43, 716-719.

48 J. Dubochet and A. W. McDowall, Vitrification of pure water for electron microscopy, $J$. Microsc., 1981, 124, 3-4.

49 A. Sorrentino, J. Nicolás, R. Valcárcel, F. J. Chichón, M. Rosanes, J. Avila, A. Tkachuk, J. Irwin, S. Ferrer and E. Pereiro, MISTRAL: a transmission soft X-ray microscopy beamline for cryo nano-tomography of biological samples and magnetic domains imaging, $J$. Synchrotron Radiat., 2015, 22, 1112-1117.

50 J. Otón, C. O. S. Sorzano, R. Marabini, E. Pereiro and J. M. Carazo, Measurement of the modulation transfer function of an X-ray microscope based on multiple Fourier orders analysis of a Siemens star, Opt. Express, 2015, 23, 9567.

51 M. Wilke, F. Farges, P.-E. Petit, G. E. Brown and F. Martin, Oxidation state and coordination of Fe in minerals: An Fe $K$-XANES spectroscopic study, Am. Mineral., 2001, 86, 714-730.

$52 \mathrm{C}$. Chen and A. Thompson, Ferrous Iron Oxidation under Varying $\mathrm{pO}_{2}$ Levels: The Effect of Fe(III)/Al(III) Oxide Minerals and Organic Matter, Environ. Sci. Technol., 2018, 52, 597606.

53 A. Vilgé-Ritter, J. Rose, A. Masion, J.-Y. Bottero and J.-M. Lainé, Chemistry and structure of aggregates formed with Fe-salts and natural organic matter, Colloids Surf. Physicochem. Eng. Asp., 1999, 147, 297-308.

54F. M. Michel, L. Ehm, G. Liu, W. Q. Han, S. M. Antao, P. J. Chupas, P. L. Lee, K. Knorr, H. Eulert, J. Kim, C. P. Grey, A. J. Celestian, J. Gillow, M. A. A. Schoonen, D. R. Strongin and J. B. Parise, Similarities in 2- and 6-Line Ferrihydrite Based on Pair Distribution Function Analysis of X-ray Total Scattering, Chem. Mater., 2007, 19, 1489-1496. 
55E. Neubauer, W. D. C. Schenkeveld, K. L. Plathe, C. Rentenberger, F. von der Kammejew Sticle Online M. Kraemer and T. Hofmann, The influence of $\mathrm{pH}$ on iron speciation in podzol extracts: Iron complexes with natural organic matter, and iron mineral nanoparticles, Sci. Total Environ., 2013, 461-462, 108-116.

56 H. P. Jarvie and S. M. King, Small-Angle Neutron Scattering Study of Natural Aquatic Nanocolloids, Environ. Sci. Technol., 2007, 41, 2868-2873.

57 S. M. King and H. P. Jarvie, Exploring How Organic Matter Controls Structural Transformations in Natural Aquatic Nanocolloidal Dispersions, Environ. Sci. Technol., 2012, 46, 6959-6967.

58 M. S. Diallo, C. J. Glinka, W. A. Goddard and J. H. Johnson, Characterization of nanoparticles and colloids in aquatic systems 1 . Small angle neutron scattering investigations of Suwannee River fulvic acid aggregates in aqueous solutions, J. Nanoparticle Res., 2005, 7, 435-448.

59R. Osterberg and K. Mortensen, Fractal dimension of humic acids: A small angle neutron scattering study, Eur. Biophys. J., 1992, 21, 163-167.

60R. Osterberg and K. Mortensen, The growth of fractal humic acids: Cluster correlation and gel formation, Radiat. Environ. Biophys., 1994, 33, 269-276.

61 V. Martin-Diaconescu, M. Gennari, B. Gerey, E. Tsui, J. Kanady, R. Tran, J. Pécaut, D. Maganas, V. Krewald, E. Gouré, C. Duboc, J. Yano, T. Agapie, M.-N. Collomb and S. DeBeer, Ca K-Edge XAS as a Probe of Calcium Centers in Complex Systems, Inorg. Chem., 2015, 54, 1283-1292.

62 J. L. Fulton, S. M. Heald, Y. S. Badyal and J. M. Simonson, Understanding the Effects of Concentration on the Solvation Structure of $\mathrm{Ca}^{2+}$ in Aqueous Solution. I: The Perspective on Local Structure from EXAFS and XANES, J. Phys. Chem. A, 2003, 107, 4688-4696.

63 D. Graf, Crystallographic Tables for the Rhombohedral Carbonates, Am. Mineral., 1961, 46, 1283-1316.

64T. D. Sowers, D. Adhikari, J. Wang, Y. Yang and D. L. Sparks, Spatial Associations and Chemical Composition of Organic Carbon Sequestered in $\mathrm{Fe}, \mathrm{Ca}$, and Organic Carbon Ternary Systems, Environ. Sci. Technol., 2018, 52, 6936-6944.

65E. Iskrenova-Tchoukova, A. G. Kalinichev and R. J. Kirkpatrick, Metal Cation Complexation with Natural Organic Matter in Aqueous Solutions: Molecular Dynamics Simulations and Potentials of Mean Force, Langmuir, 2010, 26, 15909-15919.

66R. Kretzschmar and T. Schäfer, Metal Retention and Transport on Colloidal Particles in the Environment, Elements, 2005, 1, 205-210.

67 J. D. Ritchie and E. M. Perdue, Proton-binding study of standard and reference fulvic acids, humic acids, and natural organic matter, Geochim. Cosmochim. Acta, 2003, 67, 85-96.

68 M. Auffan, J. Rose, O. Proux, D. Borschneck, A. Masion, P. Chaurand, J.-L. Hazemann, C. Chaneac, J.-P. Jolivet, M. R. Wiesner, A. Van Geen and J.-Y. Bottero, Enhanced Adsorption of Arsenic onto Maghemites Nanoparticles: As(III) as a Probe of the Surface Structure and Heterogeneity, Langmuir, 2008, 24, 3215-3222.

69O. S. Pokrovsky, L. S. Shirokova, S. N. Kirpotin, S. Audry, J. Viers and B. Dupré, Effect of permafrost thawing on organic carbon and trace element colloidal speciation in the thermokarst lakes of western Siberia, Biogeosciences, 2011, 8, 565-583. 


\section{Table of contents entry}

Calcium drives the structural transitions of iron-organic matter associations from colloidal aggregates to a non-colloidal micrometric network, subsequently controlling their mobility and the iron surface reactivity.

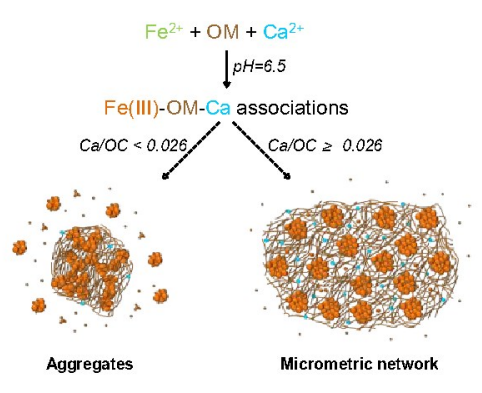

